\title{
WestVirginiaUniversity
}

THE RESEARCH REPOSITORY @ WVU

Graduate Theses, Dissertations, and Problem Reports

2019

\section{Cloud 9: Bringing the abstract to light}

Thomas N. Gillette

West Virginia University, tng0003@mix.wvu.edu

Follow this and additional works at: https://researchrepository.wvu.edu/etd

Part of the Fine Arts Commons, and the Theatre and Performance Studies Commons

\section{Recommended Citation}

Gillette, Thomas N., "Cloud 9: Bringing the abstract to light" (2019). Graduate Theses, Dissertations, and Problem Reports. 3889.

https://researchrepository.wvu.edu/etd/3889

This Thesis is protected by copyright and/or related rights. It has been brought to you by the The Research Repository @ WVU with permission from the rights-holder(s). You are free to use this Thesis in any way that is permitted by the copyright and related rights legislation that applies to your use. For other uses you must obtain permission from the rights-holder(s) directly, unless additional rights are indicated by a Creative Commons license in the record and/ or on the work itself. This Thesis has been accepted for inclusion in WVU Graduate Theses, Dissertations, and Problem Reports collection by an authorized administrator of The Research Repository @ WVU. For more information, please contact researchrepository@mail.wvu.edu. 


\title{
cloudg
}

\section{Bringing the abstract to light}

Thomas N. Gillette

Thesis submitted to the

College of Creative Arts

at West Virginia University

in partial fulfillment of the requirements

for the degree of

Master of Fine Arts

in

Lighting Design \& Technology

\author{
Alan McEwen, M.F.A., Chair \\ Radhica Ganapathy, Ph.D. \\ Steven Neuenschwander, M.F.A
}

\author{
School of Theatre \& Dance \\ Morgantown, WV 2019
}

Keywords: Cloud Nine; Cloud 9; Lighting Design; Theatre; CAC;

Gladys G. Davis Theatre; Theater; Contemporary Theater

Copyright 2019 Thomas N. Gillette 


\section{Abstract \\ Lighting Design for Carol Churchill's Cloud 9 \\ Thomas N. Gillette}

This document chronicles my journey designing the lighting for Carol Churchill's Cloud 9 in the Creative Arts Center at West Virginia University. Starting with the initial read, this paper will continue through the early meetings and initial concepts discussed by the design team. Proceeding through the evolution of the design up to and throughout the tech process and will conclude with an evaluation of the overall experience. I have also provided a combination of paperwork items which were essential in the mounting of the production including: light plot, the channel hookup, cue list, and the EOS magic sheet. In addition, there are images from initial research and from the production itself. 


\section{Dedication}

To Kellie,

I will never be able to repay you for everything you have done for me to get me through these past three years. I love you always.

To my Dad,

Who was the kindest, most gentle hearted, and most caring person I have ever known. Not a day goes by that I don't think of you and thank you for making me the person I am today. I miss you. 


\section{$\underline{\text { Table of Contents }}$}

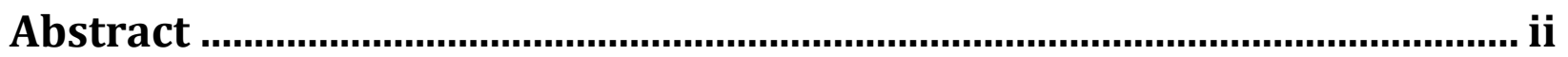

Dedication.................................................................................................................. iii

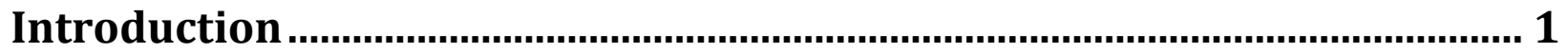

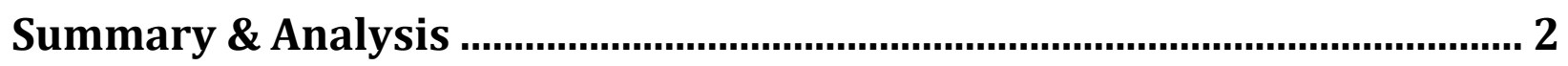

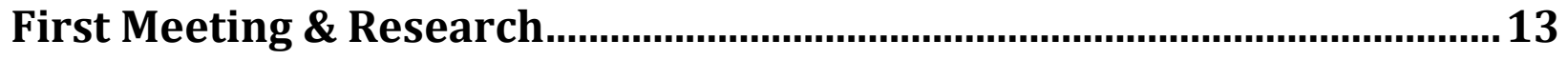

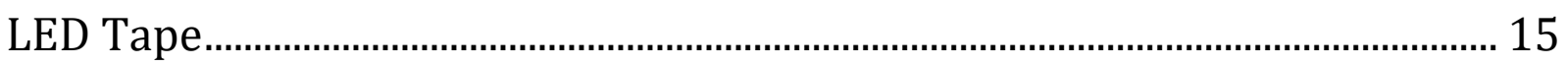

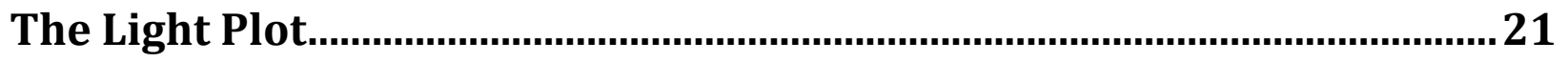

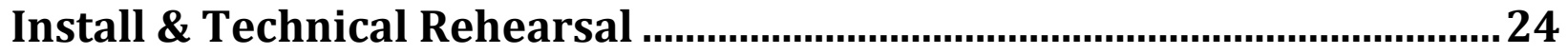

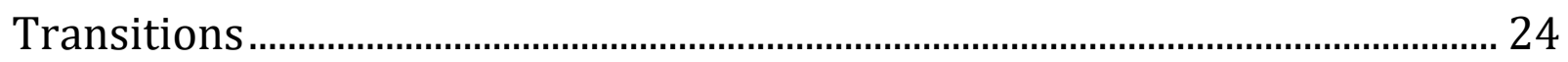

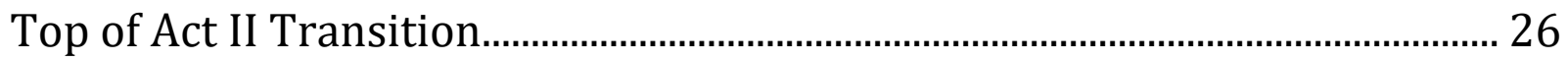

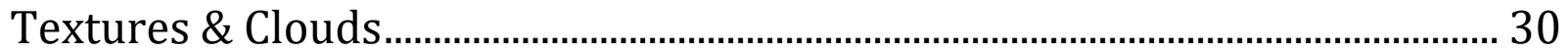

GIO

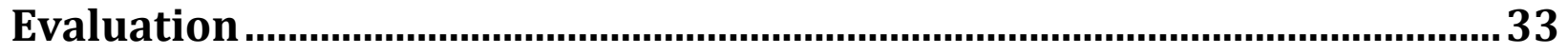

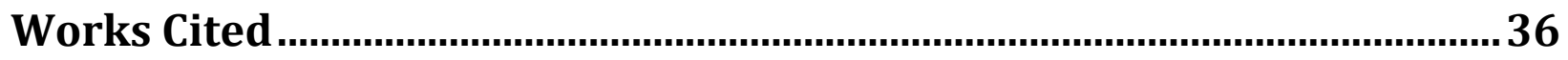

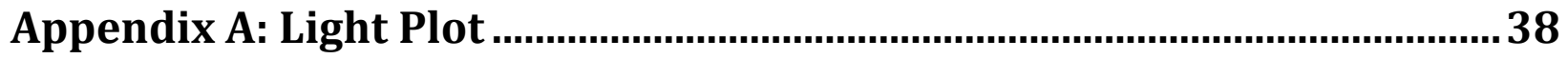

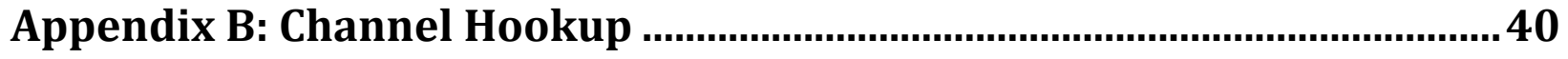

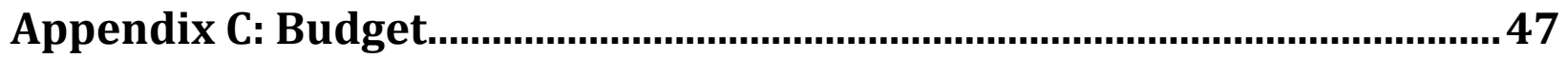

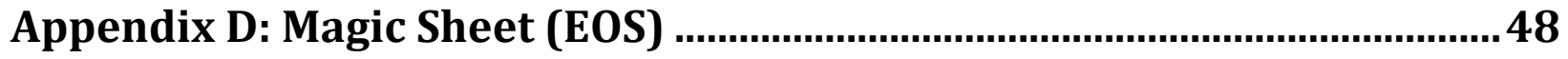

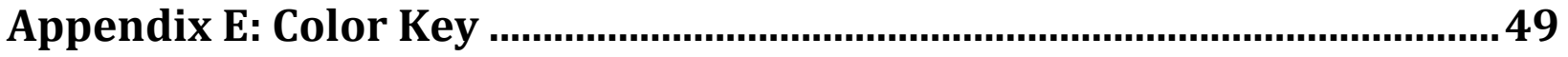

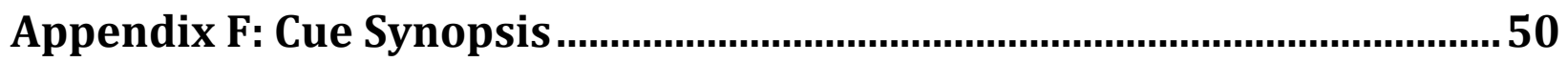

Appendix G: Additional Research Images ............................................. 51 


\section{Table of Figures}

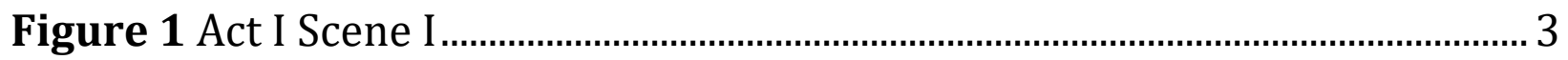

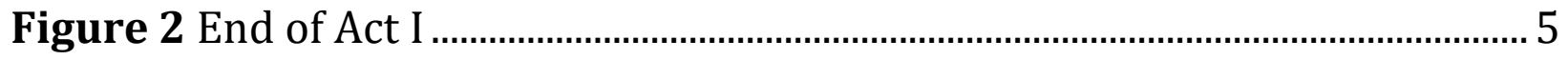

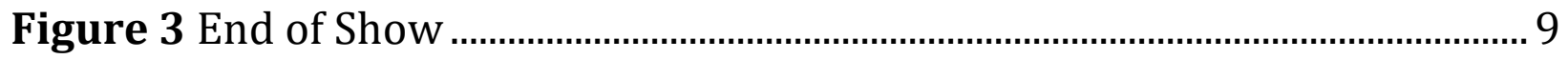

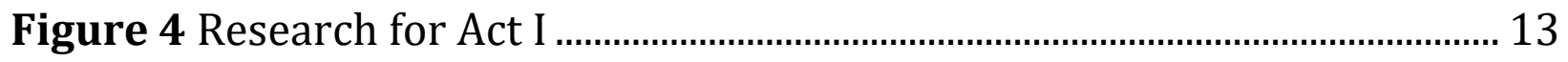

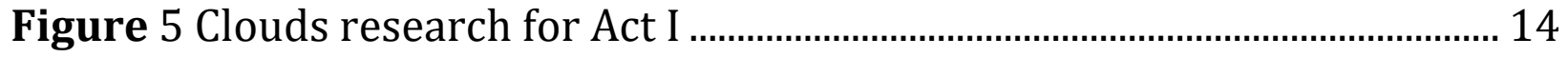

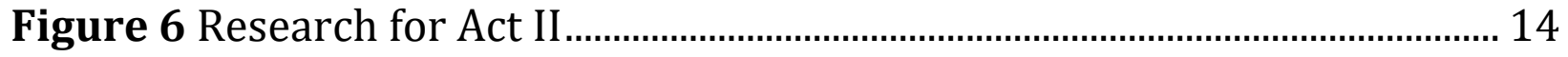

Figure 7 Research image courtesy of Lidnsay Maiorano...................................... 15

Figure 8 Act I Scale Model courtesy of Lidnsay Maiorano ..................................... 15

Figure 9 LED Tape Research....................................................................................... 16

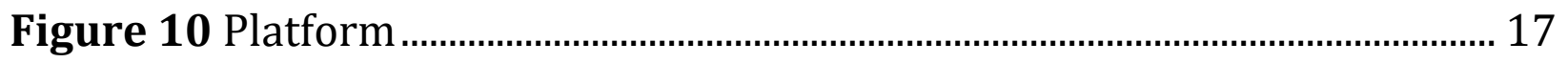

Figure 11 Research different color temperatures of white LED's....................... 18

Figure 12 City Theatrical QolofFLEX ${ }^{\circ}$ Tape ………………………………………... 19

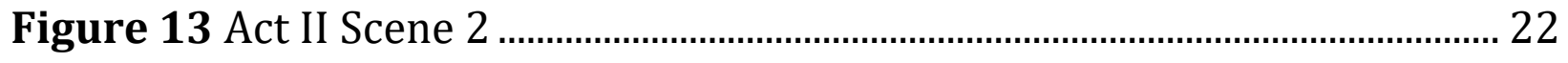

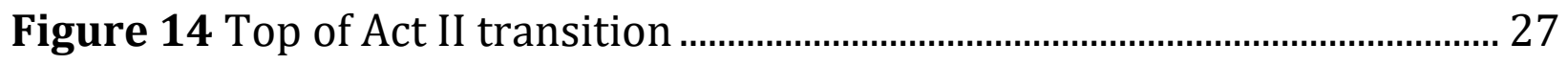

Figure 15 Top of Act II transition ............................................................................. 28 


\section{Introduction}

In the spring of 2018, I was given the opportunity to design the lighting for Carol Churchill's Cloud 9 as my thesis to fulfill my master's in Lighting Design. Opening the weekend before Thanksgiving in 2018 the production took place in the Gladys G. Davis Theatre at West Virginia University's Creative Arts Center. This production was directed by Dr. Radhica Ganapathy; the set was designed by Lindsay Maiorano and the costume designer was Laura Plikerd. Professor Alan McEwen was the Sound Designer and the Technical Director was Caila Yates. 


\section{Summary \& Analysis}

This play follows members of a prominent English family and their struggles within themselves and each other. Clive, the husband, his wife Betty, their two children, and the nanny were sent to oversee an African province of the Colonial English empire. They are visited by Betty's mother, who shows no sign of leaving, Harry Bagley, a family friend and explorer, and Mrs. Saunders, a widow who resided nearby.

The play opens with the family along with Joshua, the family servant, marching on the stage and singing. Following the song, Clive addresses the audience introducing the cast who are present (Harry Bagley and Mrs. Saunders have not entered the stage picture at this point). Betty, Clive's wife, is played by a man. Their son, Edward, is played by a woman. Victoria is Edward's younger sister and is played by a doll during Act I. Maud is Betty's mother. Ellen is the children's nanny and Joshua is Clive's native servant but is played by a Caucasian. With introductions complete the family poses for a family photograph (Figure 1) show begins; Clive and Betty speak about the 


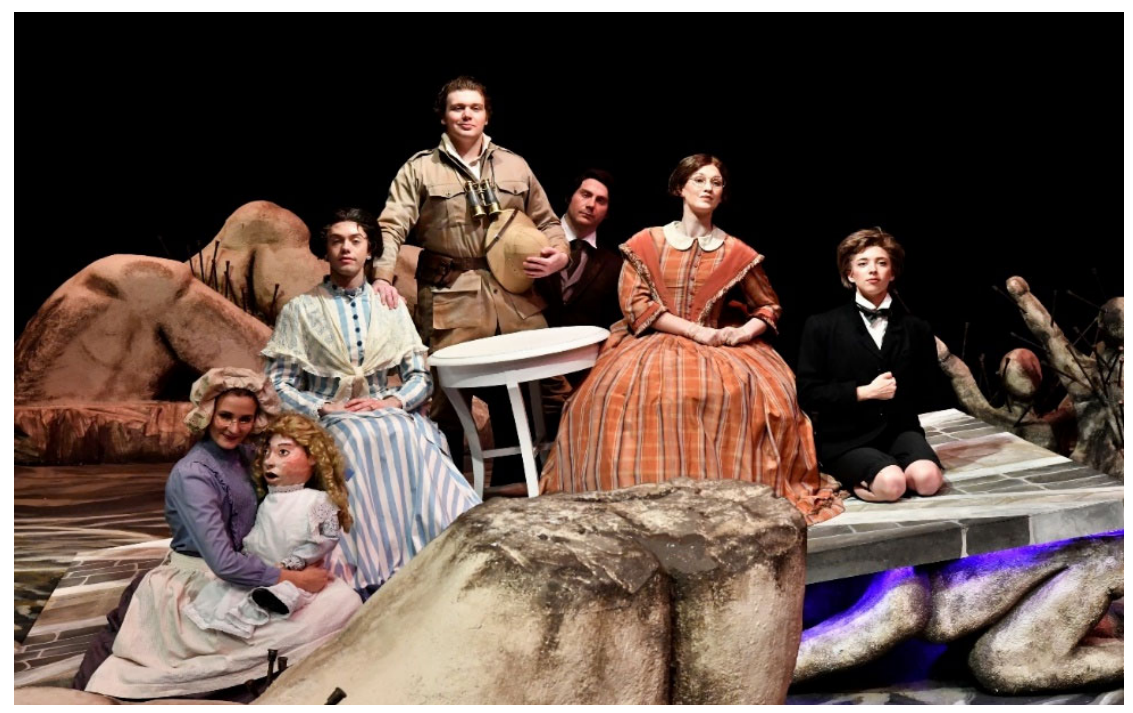

Figure 1 Act I Scene I troubles with the

natives and Betty

confesses her troubles

with Joshua. In a

display of the period,

the dominance men

possess over women

is displayed when Joshua and Clive both put pressure on Betty to dismiss the accusations she has made against Joshua. As the sun sets Harry Bagley enters and is greeted by Clive and Edward, the eldest of the two children. Mrs.

Saunders makes her entrance as she is fleeing from her home which was overrun by natives.

The second scene of Act I explores the characters' relationships further during a Christmas day picnic. As the day unfolds, we see Clive making sexual advances towards Mrs. Saunders, Harry flirting with Betty and being approached by Edward to repeat past indiscretions. Observing these interactions is Joshua who diligently informs Clive about his wife's activities. The scene ends with Joshua contemplating his position with Clive but also the treatment of his people and the predicament he has found himself in. 
The next scene opens to the sounds of the stable boys being whipped. As Mrs. Saunders exits to check on the men's progress, Edward enters with a weak stomach from witnessing the flogging and sneaks over to play with his sister's doll. Having been warned prior about playing with dolls Betty snaps at Edward, but he speaks out against his mother in an escalation which leads to Betty slapping him. Betty proceeds to blame Ellen, the nanny, for not doing her job and being the reason, she had to slap her own child. Ellen guiltily reprimands Edward and slaps him too. As Edward exits Joshua comes onstage to see if the ladies are alright followed by Clive and Harry. Edward makes a quick reentrance to explain the doll situation to his father before anyone else does. As everyone else exits to go out on the verandah. Clive confronts Betty about her recent indiscretions with Harry. Though she pleads for her forgiveness Clive says he cannot. They will continue to live as husband and wife for the good of the family, but he cannot love her as he did before.

Opening the next scene at sunrise, only Joshua and Edward are awake. At Edward's request to be told a "bad" story, Joshua tells the story of creation as per local folk lore. At the conclusion of the story, Clive comes onstage and informs Edward, Joshua, and Harry, who entered with Clive, about the events that occurred the night before; British soldiers burned down a village belonging to the natives and murdered several of the villagers, including 
Joshua's parents. Later, after a conversation in confidence between Harry and Clive, Harry misinterprets his friend and sees an opportunity to make an advance on him. Repulsed by Harry and considering the implication this could have on his name and the empire he hastily convinces Harry to marry. After being asked for her hand by Harry Mrs. Saunders proceeds to inform Clive about the atrocities of the British soldiers claimed on Joshua's parents. Harry asks Ellen who agrees to his terms, despite the fact she's not attracted to men. The final scene opens later the same day with Edward once again playing with his sisters' doll. Joshua enters and without saying a word takes the doll, cuts it down the middle drops it on the ground and exits the stage. The men enter while Clive is speaking of the wonders of marriage in an attempt to cheer up his friend. The scene ends with the weeping bride being brought in and Clive making a speech and as the act comes to a close, we can see Joshua appear and promptly raise his rifle at Clive (Figure

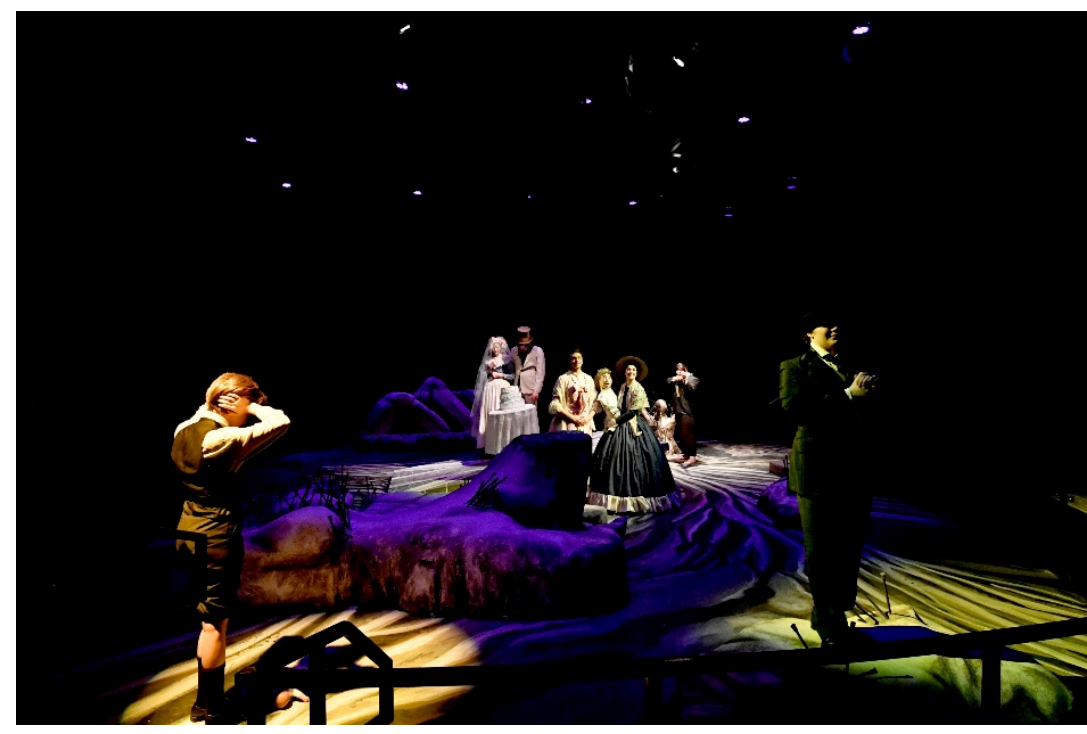

Figure 2 End of Act I 2). 
A radio broadcast starts Act II to show the passage of time; for our characters it's been about twenty-five years, but in terms of world events it's been a century. Between Act I and II the cast have taken on different roles, some familiar while others are new. For the sake of this production the actor's roles are as follows: The actor playing Clive is now playing Cathy, Betty is now Edward, Act I Edward is now Victoria, Ellen/Mrs. Saunders is now playing Lin and Joshua is now playing Martin. At the broadcast's conclusion we open up into the first scene of Act II to see Cathy, a young girl about four years old, and Lin, Cathy's mom. Sitting next to Lin is Victoria; the same Victoria who was a toddler in Act I. The scene progresses explaining Victoria is the mother of Tommy, who is never seen by the audience, and married to Martin. Lin is Cathy's mother, is divorced, and in love with Victoria. Now an adult, Edward enters and warns his sister of the approach of their mother. Though not being a false claim, Edward gets defensive when Lin asks if he is gay; asking her not to be so vocal about his sexual orientation. Betty enters talking her children's ears off and amidst her rambling she swiftly mentions she will be leaving her husband but dodges any follow-ups from Victoria and Edward as she exits. The scene ends with Lin showing her true feelings about Victoria to her. 
Scene 2 opens with Edward gardening in the park and his boyfriend, Gerry, sitting on a nearby bench. Gerry's wish for independence is made abundantly clear early in the scene; Edward keeps asking where Gerry was the night before; Gerry keeps insisting on Edward dropping the subject. Gerry breaks the fourth wall to tell the audience the story of someone he picked up on the train. The conclusion of the story makes it clear Gerry is currently solely interested in physical pleasure and not any type of relationship. After completing his monologue Gerry makes his way offstage. Betty, Victoria and Martin enter the park. Since leaving her husband Betty is having difficulty functioning independently such as her inability to comfortably walking down the street and how everything feels so overwhelming. Victoria tries to comfort her but to no avail. Temporarily giving up on her mother, she crosses to Martin who is watching their son feed the ducks. Martin comforts his wife and tells her to take the job offer in Manchester. He tells her that Tommy and himself will be fine if she chooses to take this opportunity. After continuing about their short comings in their love life Martin eventually leaves taking Betty with her who says she would be more comfortable being accompanied by a man. After their exit Victoria and Lin, who had entered earlier in the scene, embrace and Lin lets her vent about her troubles. Amidst their talks Lin breaks down and explains the death of her brother, who was stationed in 
Belfast. Lin, Cathy, and Victoria leaves and Gerry enters with Edward. Following a brief argument, they break up and Gerry exits. Victoria reenters on stage and begins to comfort her brother. They both spoke of how they are over men. After confessing his envy of his sister being a woman he asks if he can touch her breasts. With her consent, he begins to caress her. Victoria admits finding pleasure from this and Edward came to the realization that maybe he is a lesbian.

Scene 3 takes us to a late night in the park with Lin, Victoria, and Edward who are all intoxicated gathering around the fountain to perform a séance led by Victoria. The ceremony turns into an orgy which is joined by Martin who was out looking for his wife. While everyone is preoccupied the audience sees a figure approaching who Lin recognizes as Bill, her dead brother. Being the only one who can see him, Lin starts to get hysterical. With the sight of Bill, and Lin's reaction killing the mood, the group proceeds to leave. Gerry enters the empty stage and proceeds to tell the audience about his love of being alone; upon the end of his monologue, Edward from Act I comes onstage and repeats a conversation he had with Harry Bagley in the previous act.

The final scene of the show opens with Martin, Cathy, and Edward onstage. Edward, who has been caring for Tommy and Cathy, is explaining a 
medicine for Tommy to Martin. At its conclusion we see Betty enter; proudly explaining her ability to find a job, have her own flat, and pay her own bills we see a much more confident side of her, something we had not seen up to this point in the show. Towards the end of the scene Betty is left alone onstage and addresses the audience. She tells the story of how she was caught and forbidden to explore herself sexually when she was younger but had finally found that again in herself since her divorce. At the conclusion of her monologue, Clive enters onstage and harks back to a previous moment of the show featuring his view of the empire and what it meant to be British. Upon Clive's exit, Betty from Act I comes onstage and the show ends with both Act I and Act II Betty's facing one another (Figure 3).

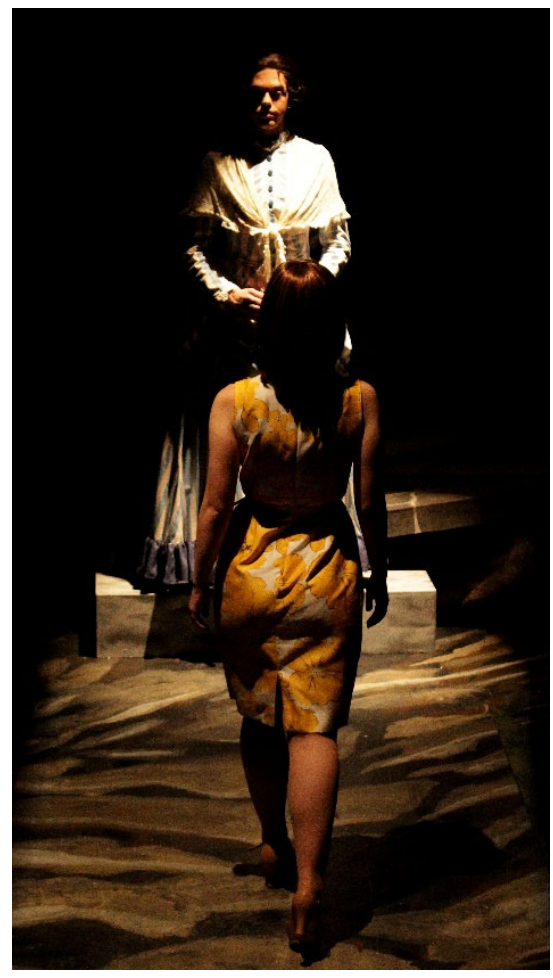

Figure 3 End of Show

The challenges Cloud 9 presents lies in the density of the subject matter and metaphors Churchill presents to her audience. It's not the locations of the show that is the challenge but rather the presentation of the show to the audience. It is stated in Helene Keyssar's The Dramas of Caryl Churchill: The Politics of Possibility, "Churchill created a script that asserts the inseparability 
of class and sexual oppression and calls into question the rigidity of our perceptions of human beings as men and women."

I initially had trouble visualizing the change of characters between the two acts and the reasons behind the choices made by the playwright and Dr. Ganapathy, the director. It was not until seeing a run through of the show that I understood the character change from Act I to Act II and how to design around this. The script does not call for any specific scenery at the top of either act; while there are references to specifics such as the balcony in Act I or the fountain in Act II Churchill has granted the production team a much larger blank canvas to work from.

"The precision of Churchill's language bites, and there is never a verbal action we cannot understand unless we refuse to." (Keyssar 214) Churchill makes bold choices when it came to her presentation of the characters, particularly in Act I. Keyssar points out how all the characters in Act I are "exaggerated stereotypes of their given roles," but as the Act progresses, everyone else breaks the mold of what is expected of them (Keyssar 213). Joshua, a slave who aspires to be respected and regarded as an equal is played by a white man. Trying to push down his personality in an attempt to appease his strict father, Act I Edward is played by a woman. These clever choices by 
Churchill and Dr. Ganapathy assist the audience member to better understand the question of gender and the roles they have played throughout history. By gender swapping the role of these characters Churchill openly presents who these characters truly are and strive to be. "By retaining essentially the same family, though placed in an ostensibly different world, Churchill provides some genuine continuity for the spectator; she also extends our political understanding that over the course of the last hundred years, family structure has altered but at a slower pace than have the ornamental aspects of social life. In 1982, Victoria can end up living in a menage of five with her woman friend, Lin, her brother, Edward, her own child and Lin's child, all of them sharing a bed together, but parent-children relationships, domestic roles, attitudes towards work, and assertions of power remain remarkably similar to those of Victorian England." (Keyssar 214)

Clive represents the typical gender role of men in western culture during the nineteenth century. He instills his dominance at the first chance he gets by stating, "My wife is all I dreamt a wife should be. And everything she is she owes to me." (Churchill 6) Throughout the show one can find Clive taking pleasure in being the source of authority and quick to pass over his own faults, and the faults of other men of the period, on to women. Constantly referring to 
them as the "weaker" sex and quick to throw blame on women as well, Clive is in no way a likeable character. Following the Act II transformation, the actor playing Clive goes on to take on the role of Cathy, a four-year-old girl who is in constant need of attention from her mom.

Betty is the character who makes the largest transformation of the cast. Towards the end of the show she finds herself again, though she is still haunted by her Act I persona who was oppressed by Clive at every turn. Dr. Ganapathy's direction clearly displayed the power men had over women during the $19^{\text {th }}$ century. For example, In Act I Scene 1, Betty confesses her difficulties to Clive with how Joshua treats her when he is not around. Clive and Joshua both gang up on her to have her drop the subject. This early moment in the show vividly sets the tone of the act and shows the power even Joshua has over her despite his position and complexion. Later in Act I there is an insight to the hierarchy of the family. Edward chooses not to listen when beckoned by Ellen for breakfast. Edward gets told to go inside the house in quick succession by Ellen, then Betty, then finally Clive who has the final word on the matter. 


\section{First Meeting \& Research}

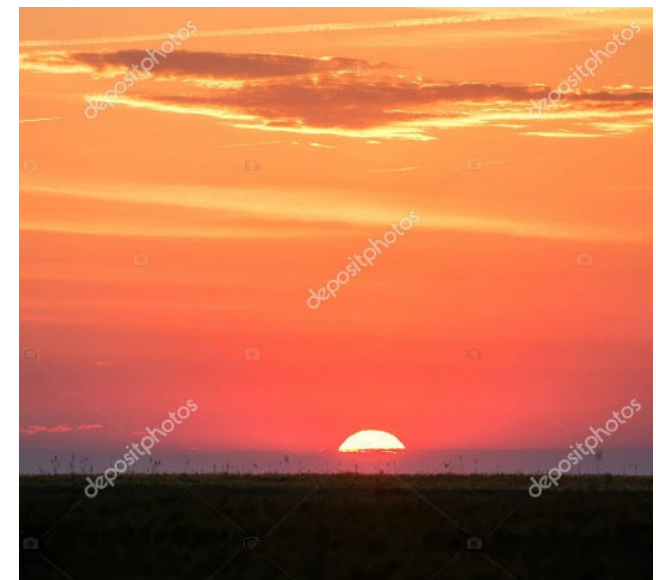

Figure 4 Research for Act I
As the Spring semester of 2018 was

wrapping up, the production team met to get the ball rolling and discuss our creative approach to this production. Dr. Ganapathy presented a power point to display some of her initial thoughts and some key adjectives;

expressionism and juxtaposition were the two she highlighted the most.

Dr. Ganapathy used examples such as abnormal coloring, telegraphic speech, exaggerated shape, and distorted lines; typical devices for the audience to see beyond the surface.

Going off Dr. Ganapathy's wish for juxtaposition in the play between the English family and the landscape of Africa, I wanted to assist scenic and costumes in creating an atmosphere where the European settlers would clash with their surroundings, so they would look and feel out of place. Initial research led me to examine sunrises and sunsets of the African savannah (Figure 4); the warm colors were the base I would use to build my color palette for Act I. The rolling clouds one can find led me to the idea of creating 
an effect to simulate the feeling of sweeping clouds (Figure 5)

granting the actor's a brief pause from the onslaught of the sun. Act II's setting of London made sense for the characters to feel more suitable. England's reputation for

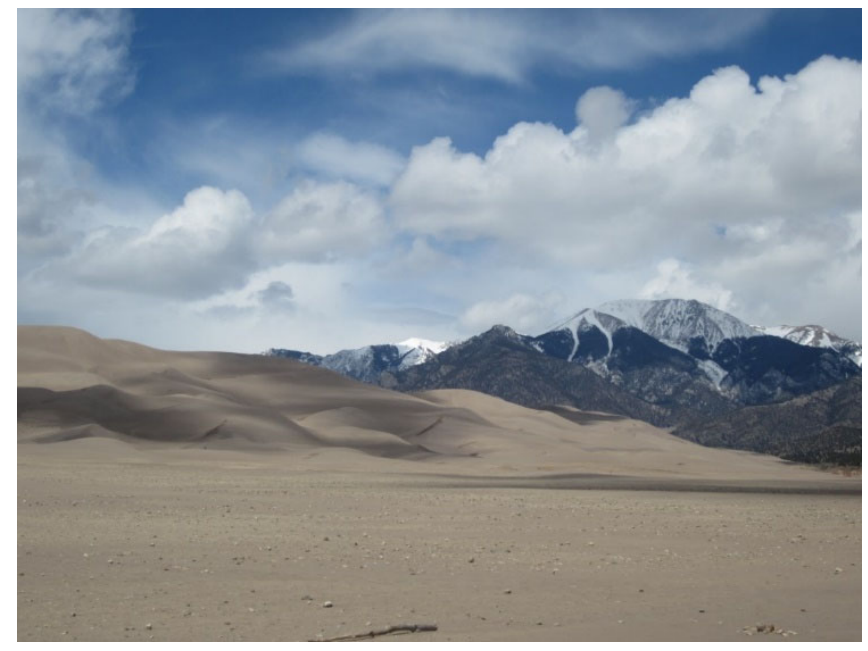

Figure 5 Clouds research for Act I

high amounts of overcast gave me the inspiration to give the second act an overall cool color palette. These two aesthetic choices and the passage of time between each act would create an episodic feeling Dr. Ganapathy asked for during our initial meeting. As Act II progresses, we begin in winter and end in spring. For the end of the show I sought to get rid of the overcast and let the sun shine through the park foliage (Figure 6) to give the characters a breath of fresh air. With the time of year, this sunlit environment

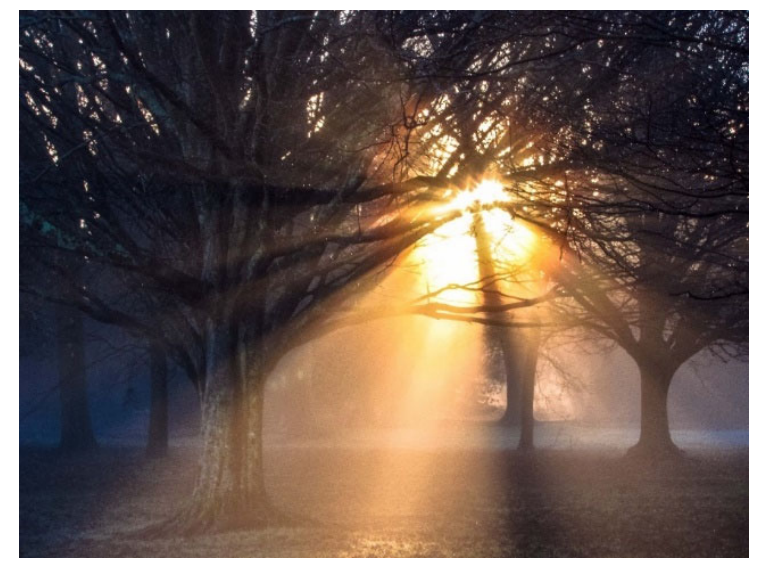

Figure 6 Research for Act II suited the final scene because so many of the characters had at last found happiness with either their respective relationships or even themselves. 


\section{LED Tape}

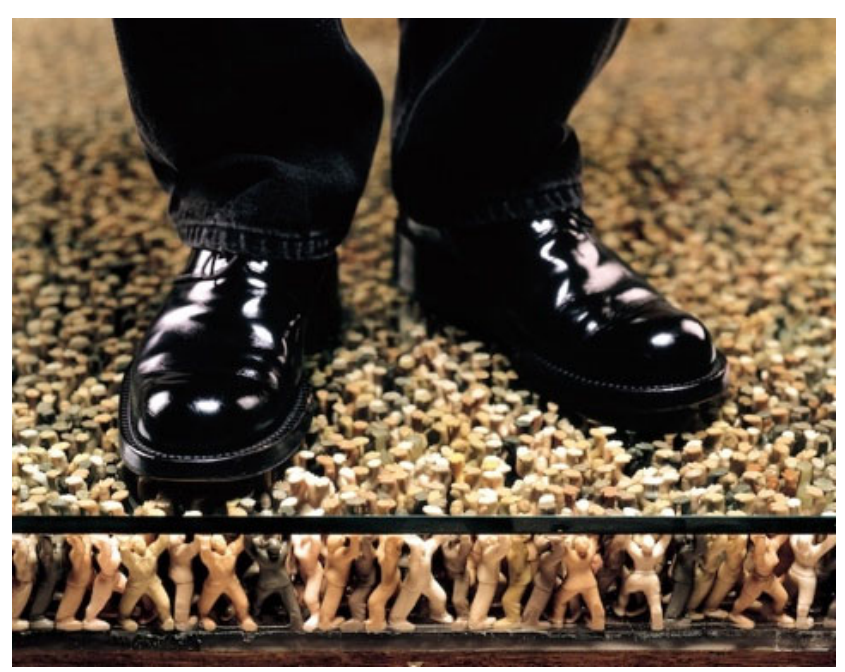

One of the most interesting portions

of the scenic designer's research was

a floor installation by South Korean

artist Do Ho Suh which consisted of

thousands of small-scale figures

holding up the glass floor for people

Figure 7 Research image courtesy of Lidnsay Maiorano

to walk on freely (Figure 7). The piece was open to interpretation as to whether the figures were holding you, the attendant, up or were they holding on for dear life trying to not be crushed by you? Using this image as a foundation, Ms. Maiorano used this concept as inspiration to create a platform which was supported by sculpted figures holding up a

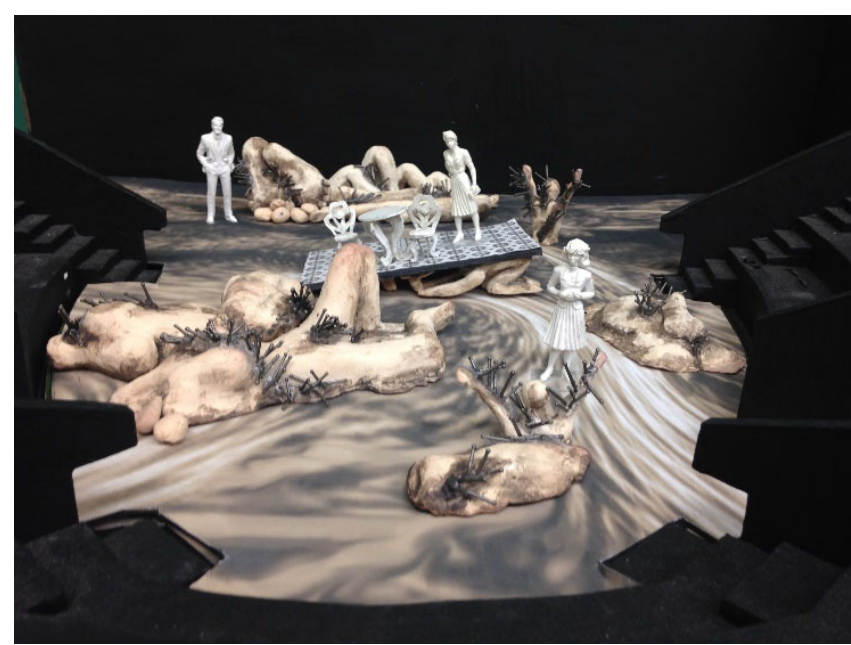

Figure 8 Act I Scale Model courtesy of Lidnsay Maiorano

platform (Figure 8) which would serve as the gazebo in Act I and would have the fountain installed at the top of Act II. We each independently had the idea of lighting the bottom of the platform to help highlight these figures and give a modern touch to the set (Figure 9). 
I Initially played around with the idea of utilizing small pin spots to light the bottom of the platform but was concerned about only backlighting the sculptures which was not an aesthetic Ms. Maiorano or myself desired. We wanted to sculpt the figures as you would the body of a performer; allowing the highlights and shadows to define these figures so they appear as more than just rock formations holding up the platform. I also wanted to have the freedom to change color on the structure but maintain the minimalist modern aesthetic. Correspondingly I began the exploration into the possible acquisition of LED Tape.

Due to the inventory at WVU to pull this off my show budget would have to purchase the tape, power supply, and the DMX control box and still have enough money left over to buy gel for the two-week run. Through my research I found that LED tape is relatively inexpensive; however, quality LED tape starts to go up in cost

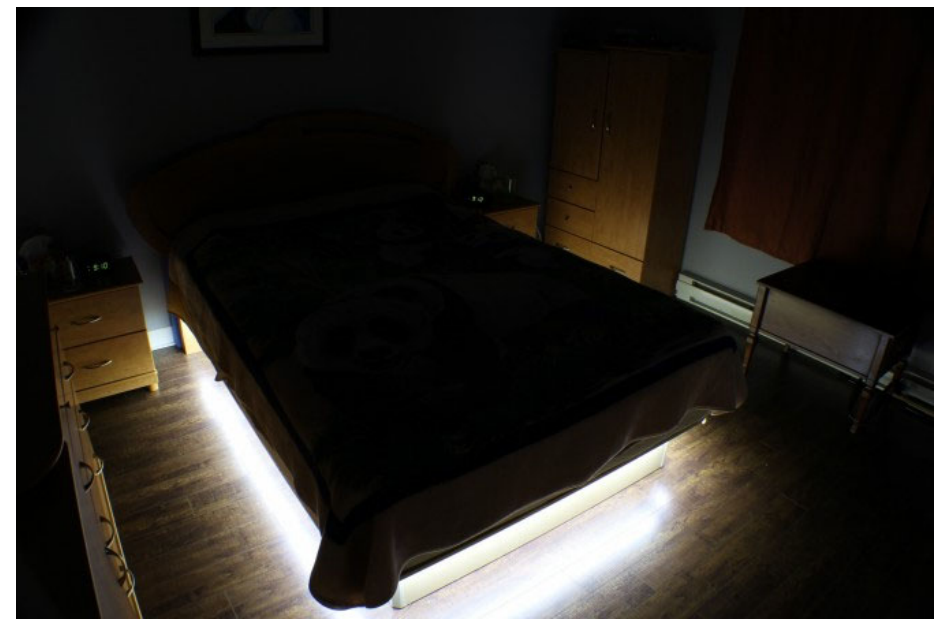

Figure 9 LED Tape Research rather quickly. What made it pricey was the need for good color blending, this means there needs to be enough pixels close enough to give a constant state of color. In cheaper LED's, especially strip lights, it is easy to spot the blending 
issues which injures and sometimes breaks the visual. The second aspect I was focusing on was intensity. I did not want this to be just a constant source of light throughout the show, I wanted to have the ability to make the platform an accent to the overall aesthetic as well as a centerpiece at times during the production. The ability to blast the platform (Figure 10) with light was

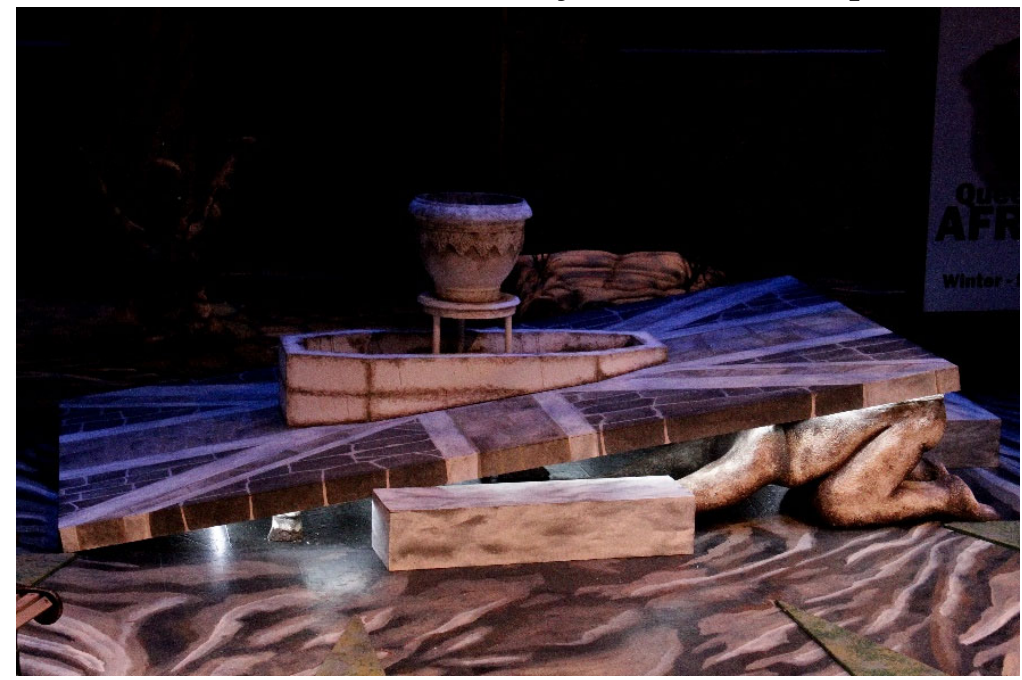

Figure 10 Platform important to accomplish for the desired effect. Some companies get devious in how they advertise a product; many cheaper companies will boast how bright their product is but will only be referring to it's all white setting, which means all the LED's are working at full to create white light. The problem with this is if the operator tries to utilize a purple in an RGB equipped product, you will be turning down the green and losing overall intensity.

Color was the third aspect which drives the price on LED products. Manufacturers make many different combinations of color, and pure white. For the longest time, LED products were either White (W) or Red, Blue, Green (RGB). As LED Tape became more widely used, consumers discovered new demands of functionality. One of these revelations was the desire to create 
warmer tones; the inclusion of amber became available, but at a premium. Products can be found now in combinations such as Red, Green, Blue, Amber (RGBA) and Red, Green, Blue, Amber, White (RGBAW). To go along with choosing the combination of colors, the decision had to be made on the color

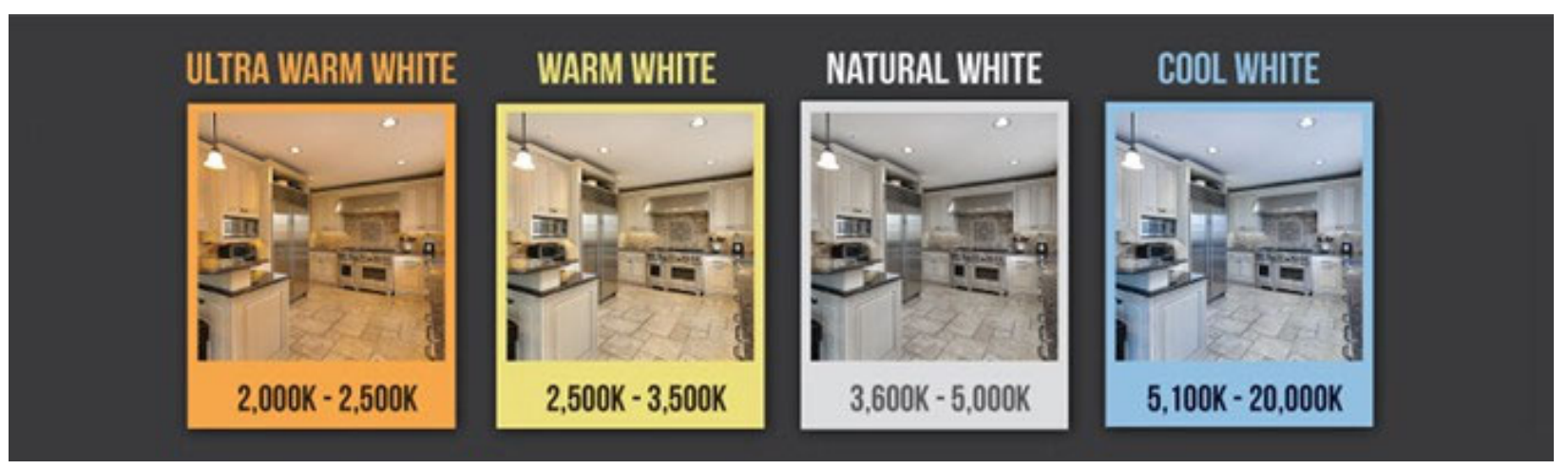

Figure 11 Research different color temperatures of white LED's

temperature of white as well. One of the biggest complaints by many lighting designers is the color temperature of white created by LED's. When talking about the hue and saturation emitted by white LED's we are talking about their correlated color temperature (CCT). According to superbrightleds.com, CCT is measured in kelvin( $\mathrm{K})$ and typically ranges between $2,000 \mathrm{~K}$ and $20,000 \mathrm{~K}$. As noted in figure 11 Ultra Warm white, which ranges more on the amber side, lies between 2,000K and 2,500K. Typically recognized modern incandescent lamps, warm white is between $2,500 \mathrm{~K}$ and 3,500K. Natural white lies between $3,600 \mathrm{~K}$ and $5,000 \mathrm{~K}$ and Cool White ranges from 5,100K to $20,000 \mathrm{~K}$. Knowing which range you are looking for eases the process tremendously and helps narrow the price point. 
City Theatrical has a line of LED tape (Figure 12) which we were fortunate enough to have demoed for us by Artistic Concept Groups during a visit earlier in the semester. City Theatrical's product was quite impressive and worked well, but due to their price point was just not a possibility for my

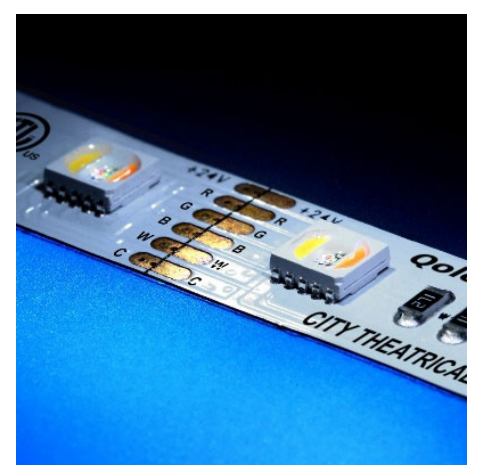

Figure 12 City Theatrical QolofFLEX® Tape
\$650 budget. Justin Burns, another Lighting Design

Grad Student, had worked with LED tape at his

undergrad institution and had suggested looking at

superbrightleds.com. They are a U.S. based company

which sells a myriad of LED products. Inventory from

cheap to exquisitely expensive, this company had exactly what I was looking for.

I finally decided on a 50/50 tape which means that the way the lighting sources spread goes white, multicolor, white, etc. Justin Burns, who was the lighting designer for Magic Flute the next semester, knew that he wanted to also utilize LED tape in his set. We agreed that the 50/50 tape would work and pooled our budgets together to make a larger single order. Luck had it that when we went to make the purchase there was a deal going on which gave us a fifteen percent discount for our purchase and a free mouse pad! After the discount the final price for the order was $\$ 710.55$. This being over my show budget of $\$ 650$, we combined budgets from Magic Flute, Cloud 9, and a couple 
of other resources for this investment. I spent $\$ 422.55$ of my budget on the LED tape and accessories but because we already had in stock the gobos I desired the only remaining item I had to purchase was color for my conventional fixtures. 


\section{The Light Plot}

Before drafting the plot, I had many questions about the blocking which could only be answered by watching a rehearsal. Luckily there was a run through of Act I that I was able to attend before the drafting was due. After attending rehearsal, I concluded that I did not have to worry about isolating with my color systems because any special I needed would have to be very tight and specific.

The Gladys Davis theatre has one of the most unique grid systems I have ever seen, and I have come to have a love and hate relationship with it. The biggest gripe I have is the inability to hang on center without going through far more trouble than it is worth. The venue is set in a permanent three quarter thrust which as a lighting designer creates a different set of challenges compared to designing in a proscenium space. Instead of lighting with a typical key and fill light as one could do with a single audience perspective I lit the show with washes to create a dynamic look on the scenery and the actors. The goal of these systems was to keep the performers from looking flat or monochromatic. I had to accept the fact not every audience members visual experience would be the same.

With the inventory of the Davis Theatre I had enough fixtures to have four full stage washes for fill. Given all the money in the world I would hang 
systems from the upstage as well, but I felt that was ignoring audience sitting straight front and would then widen the gap of the experience for audience members in other seating sections. These four systems of front/side light became the foundation of any cue I wrote for the show (Appendix D). Thankfully I had access to an LED top wash for the system which I would come to rely on for any super saturated colors.

I love using texture in a design and while I personally wanted to have texture in both acts I thought it would be more powerful to take it away in Act I and have an abundance in Act II. Ignoring the use of texture in Act I allowed

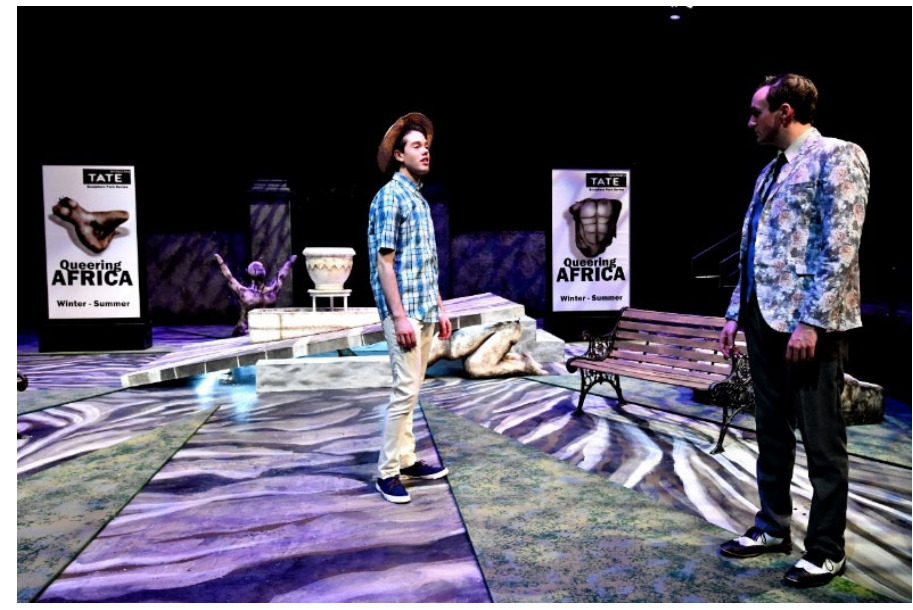

Figure 13 Act II Scene 2 me to create a stronger contrast

between the two acts. For example, for Act II's modern setting I felt permitted to take some further liberties with the aesthetic as these characters try to navigate through their very realistic problems. I wanted to seize the opportunity to use textures which were unrealistic; I used a system of diamond lattice and another wash of choc block (as seen in Figure 13) which would subtly give the stage a different feel as opposed to using a traditional natural breakup or leaf breakup. 
Each of my main systems consisted of eighteen lights to get a clear wash across the entire acting space; to save on dimmers I two-fered them to a dimer. There is a blessing and a curse behind this train of thought. By twofering I lose the ability to intensely isolate the action on stage with my main wash systems. However, by two-fering the majority of the plot I had the liberty to hang as many specials I would conceivably need. In addition, I also chose to utilize three movers; one Varilite 1000 and two Clay Paky Alpha Profile 700's. These movers were utilized for the top of Act II transition and moving specials where possible. 


\section{Install \& Technical Rehearsal}

\section{Transitions}

In conjunction with Dr. Ganapathy and Professor McEwen we devised the aesthetic for the scene transitions in Act I. Dr. Ganapathy desired for the transitions to feel a part of Africa. For each transition the tempo was faster than the one prior to display the building tensions between the tribes and settlers. The New World Ensemble, a percussion group at WVU, were gracious enough to lend us their talents and invited Professor McEwen to record them. Dr. Ganapathy's vision for each of the four transitions in Act I was for them to build up and get more "aggressive" in terms of the drum beat tempo as the show progressed. Lighting for each transition was a series of follow cues built so the stage manager only had to initiate the transition with sound and let the light board do the rest of the work. Time code was not utilized because the Act I light cues were not called until after the crew concluded their transitions. We could have utilized time code for Act II but decided the transition was simple already and did not foresee any reason to hook it up. Working off the different pieces of music for each transition I built and timed each transition to line up as close with the music as I could. The result for the lighting was simple to program but cumbersome to edit. Each cue had two or three lights come on at a time and a follow time allowed them to all work in an automated sequence. 
The idea was for the scene to also be in a transition "look" so the crew could make their shifts to the set. Once they were offstage the stage manager called for the next cue which would reveal the scene starting one area at a time. While I was overall happy with how the aesthetic turned out there were a couple of practical complications as well. First, the crew was not always consistent when it came to how fast they could conduct their scene shifts; this caused the music to end while the light cue was still in process. Second, the editing of the cues was not my favorite experience. Any changes I made to a particular scene in Act I forced me to edit each follow cue of the entire scene shift so there would be no adjustments in intensity once the follow cues were completed.

Act II's scene changes used sound effects that were of a series of children laughing to simulate the playground in the park. This made the scene changes stylistic and fundamentally different from Act I. The lights faded to just the top wash being up and the next scene revealed itself by sweeping across from stage right to left. The direction of the sweep was consistent throughout the act for uniformity. I was overall happy with the final result of these transitions; it felt like each scene was turning the page of a book and played well with the sounds Professor McEwen designed for the sequences. 


\section{Top of Act II Transition}

Dr. Ganapathy wanted to visually display the transformation of the cast

from their Act I characters to their new roles in Act II for the remainder of the show. The shift would also push the show forward in time, twenty years for the actors but also one hundred years in the timeline of world events.

When I was told the final decision on the transition was for the actors to dance to Queen's “Under Pressure” I must admit I was quite excited at the prospect. Dr. Ganapathy agreed with my approach to reflect concerts of the 1980 's, her one stipulation being the audience must be able to see the actors

at all times. I wanted to capture the magic you felt during a concert during the seventies and eighties which did not possess any LED fixtures and any moving lights were still in its infancy. The vast majority of these shows were lit by PAR fixtures. Concerts consisted of hundreds of these fixtures with a single color in them and equipped up to 1000 watts, compared to your typical house lamp which produces about 60 to 70 watts per fixture. I strived to recreate this nostalgic aesthetic by utilizing ETC Source 4 PARs. These fixtures are smaller and stubbier than a PAR 64 but are more energy efficient, allowing me to two-fer more fixtures together and save dimmers for the rest of the show. I lined the furthest upstage, most stage left, and most stage right sections of the grid with these fixtures. I alternated the color in each fixture between R79, 
very close to primary blue, and R26, a slightly lighter than primary red, but a higher transmission level to achieve maximum brightness. Through a series of step and absolute effects the Source 4 Pars worked perfectly and gave the concert feel I was striving for.

For the transition itself, we start Act II exactly how we left our characters at the end of Act I, all in silhouette with Joshua pointing his rifle at Clive. One by one the actors slowly made

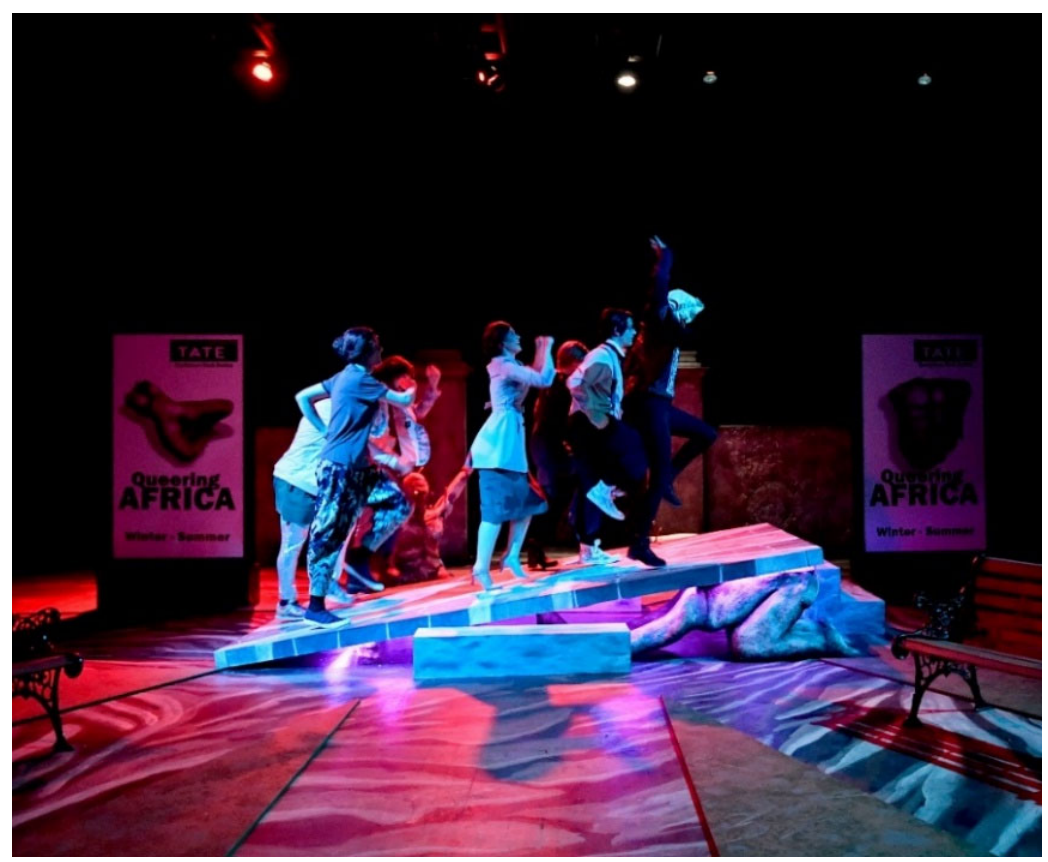

Figure 14 Top of Act II transition their way to Clive who was on top of a small rock formation downstage left. As the actors were doing this all light on stage was directed to the crowd in the same stark yellow color the audience has seen up to this point in the scene. Clive was the first to break formation and slowly the rest of the cast followed suit. They proceed to put on the costume pieces of their Act II characters as they start singing Queen's “Under Pressure." After the change is complete, they spread across the stage while continuing to sing. Once in position, the music track starts and on a zero count the concert portion of the transition 
begins. The Pars which were gelled blue and red started doing a chase sequence while the actors got in place to start their dance routine on the upstage center platform (Figure 14). The performers were lit with specials to ensure they were visible despite any other effects running throughout the sequence.

The scenic designer cleverly laid out the park for Act II by creating a Union Jack on stage with MDF painted to give the illusion of grass; AstroTurf was originally desired, but was cut due to budgeting. I wanted to take advantage of this choice and highlight it for the show. At the musical climax of the transition the actors lift one of their fellow cast members on the platform (Figure 15). To play off the energy of the track and the performers I felt the need to break the mold of what the

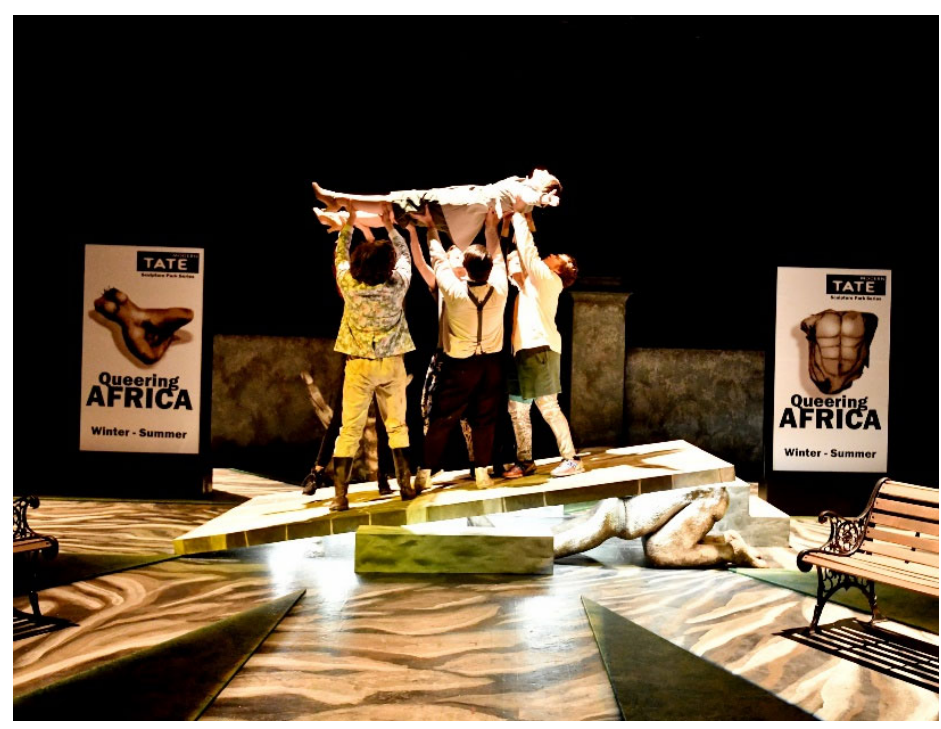

Figure 15 Top of Act II transition audience had seen up to this point in the sequence. With grass painted triangles forming the Union Jack of the park I decided to fill the negative space with no-color light from Source 4's. Besides the two fixtures used to light the platform, all others were put on an independent circuit. In the spirit of Freddy 
Mercury, I felt the need for a little flair. All the lights surrounding the platform were inserted into a chase effect to give movement to the Union Jack. The final part of the transition was a radio announcement about the weather and traffic of London. The goal behind this radio sound was to establish a backdrop and to inform the audience of where and when the show is taking place.

In early talks the team discussed displaying major events between the late $19^{\text {th }}$ century and present day. While projections were a strong hope we lacked the means to pull off what we wanted. Flashing visuals of iconic moments of history in the fashion we wanted seemed too distracting from what Dr. Ganapathy had in mind for the actors' choreography. We also discussed putting up a display board in either the inner or outer lobby of the theatre for patrons to observe during intermission; unfortunately, we were afraid of extending the run time of the show and felt the display would not accurately transmit the sensation of time passing to the audience. When we got to technical rehearsals, we had signs which were reminiscent of a picket sign from a protest that an assistant stage manager would stand and flip as the transition progressed. Upon running the transition, we all found and agreed the signs were too distracting and were afraid the audience would not be sure where to be looking on stage. In the end the signs were cut because they were found to be distracting and sight line blocking the choreography of the actors. 


\section{Textures \& Clouds}

The moving cloud effect was not as successful for Act I as I had hoped. Perhaps it was too realistic to the rest of the production. I kept it and luckily some of the audience members chuckled or laughed at the awkward silence inspired by the effect. Upon reflection I'm honestly not certain what I would have done differently to ensure more success.

The Act II textures were initially slightly fuzzed out for a subtler aesthetic and made the actors appear to walk in and out of dark spots in the light. To combat this, I had both systems focused to their maximum sharpness. The result obviously made the shapes of the gobos far more visible, and I quite fell in love with the new aesthetic.

\section{GIO}

Due to our relationship with Electronic Theatre Controls (ETC) I was given the opportunity to program the show on their GIO lighting console. The board was on loan to us during the week of load in and remained in our possession until the show opened. Knowing the GIO would not be in our possession for the duration of the run we decided to keep our ION Classic console as the primary and used the GIO as a client. By doing this I was able to program the show with the GIO from the house of the Davis Theatre while keeping the ION and the board operator in the booth. We had given ourselves 
different users on the show to allow both myself and the board operator keep working on the show file simultaneously and not be on top of each other.

The layouts of the previous generation of EOS consoles, including our ION classic, was unique to each individual board. One of the many improvements to the latest generations of EOS consoles was a universal key layout that standardized the location of keys which allowed an operator to switch between boards with ease.

During any technical rehearsal the last thing one wants is to be the person everyone else is waiting on to continue the rehearsal; every member of the production team does plenty of prep work to ensure they can work as quickly as possible. To ensure programming and tweaking of cues could be accomplished more efficiently I created a virtual magic sheet which I made accessible on one of the external touch screen monitors to allow quick selection of any part of the rig (Appendix C). With the overhead layout of the plot I was able to see which fixtures were on and at what intensity. One of the major advantages presented on any EOS console is the ability for the magic sheets to display any intensity or color changes occurring in real time; this feature allows the lighting designer to see how effects are happening in real time. 
Using this board, it's layout and capabilities proved to be indispensable in my process through programming and technical rehearsals. The multiple touch screens ensured I had all my essential tabs open and readily available. My only frustration with the board is for certain tabs the built-in monitors were slightly too small for me to be as accurate as desired at times.

As a whole, the install, technical and dress rehearsals happened without any concept defining alterations. Not to say everything was perfect or nothing required adjustments; there were a couple of specials added either to fill some unfortunate dark spots in systems, but as a whole, the entire experience was one of the least stressful processes I have ever been a part of. My Master Electrician, Akasha Poindexter, was always on top of her work and managed the crew very well for which I am very grateful because it allowed me to focus more on the design aspect rather than worry about the implementation. The only uncertainty occurred during the dress rehearsals. A number of the costumes in Act II received changes throughout the tech process. Some slight changes you might expect while others were drastic. Thankfully I only had to adjust levels to compensate for the colors on the performers as opposed to feeling the need to swap out entire system colors. Technical rehearsals consist of a lot of give and take and you must be willing to roll with the punches. 


\section{Evaluation}

I'm overall more content with the final product of the design rather than in love with it. As with any project there are changes I would make if I had more time, but this is the reality of the industry we work in.

Many issues I had with my initial design choices were in Act I. I fear I went a little harsher with the Act I colors than I should have. I wanted to keep the vibrancy because there was definite beauty in the setting but wanted to alienate the cast in this environment. Every time I took out the pink saturate colors the set felt so barren, almost post-apocalyptic, which was far from what I was trying to convey. The isolation of the center platform was a continuous struggle for me as well. the platform represented the gazebo throughout Act I, excluding scene two. I was never quite satisfied with my attempts to isolate the platform which at its peak was not more than three feet off the deck. After some shifts of light and refocusing I was forced to accept actors who were crossing down stage of the platform would be caught in the light focused on the platform.

The LED tape was one of my favorite aspects of the show. Having never had the opportunity to work with it before I was pleasantly surprised with the ease of installation and operation. The product's small profile really gave me the look I wanted for highlighting the scenic designer's sculptures holding up 
the upstage center platform. Complimenting the Scenic Designer's already modern scenery was definitely a great experience. This was the third show I had the pleasure of collaborating with Ms. Maiorano and it's always a positive experience.

Concerning the top of Act II transition, I was quite pleased with the result. I felt I captured the aesthetic with enough flair and helped create an experience which stood out from the rest of the show. I am thankful to Dr. Ganapathy for giving me creative freedom. The constructive criticism given by Dr. Ganapathy and Professor McEwen proved to be very helpful in fleshing out the sequence.

Given more time I would have tweaked the color selection of my systems. The R302 was not as successful as I had hoped; I am fond of using this color in window specials to give off a nice pinch of sunlight but as a stage wide system I found the color to be surprisingly over powering and flattening. The added special for the ghost in Act II scene 3 was fine, but I wish I had done more with it; possibly try to do more of a side light look to flesh out the figure rather than the high backlight I used.

Due to the complexity of this show, establishing an aesthetic was one of my greatest challenges. Churchill's visualization on gender roles and identities crams the audience with a lot of information and emotions to feel for these 
characters and the world we live in. The presentation of this show is so open I initially did not know where to start but upon further examinations and through meetings I was able to come up with a concept that I believe benefited the script and the production. 


\section{$\underline{\text { Works Cited }}$}

"Beautiful Sunrise Or Sunset In African Savanna With Acacia Tree, Masai Mara, Kenya, Africa Stock Photo - Image of Sunrise, Africa: 85166932." Accessed September 10, 2018. https://www.dreamstime.com/stock-photo-beautifulsunrise-sunset-african-savanna-acacia-tree-masai-mara-kenya-africanational-park-image85166932.

end2end. "DIY Bedroom under the Bed Led Lighting." end2end zone, September 1, 2014. https://www.end2endzone.com/diy-bedroom-under-the-bed-ledlighting/.

Inc, Depositphotos. "Horizon Line of Countryside with Sun Setting." Depositphotos. Accessed September 10, 2018. https://depositphotos.com/178097158/stock-photo-horizon-line-ofcountryside-with.html.

"Horizon Line with Sun Setting." Depositphotos. Accessed September 10, 2018. https://depositphotos.com/164585004/stock-photo-horizon-line-with-sunsetting.html.

“Savanna Sunset." Depositphotos. Accessed September 10, 2018. https://depositphotos.com/82515302/stock-photo-savanna-sunset.html.

“Trees Silhouettes at Sunset." Depositphotos. Accessed September 10, 2018. https://depositphotos.com/163323294/stock-photo-trees-silhouettes-atsunset.html.

Jeremy. "Hiking in Sand Dunes: A Traveler's Guide | Jeremy Anderberg." Accessed September 10, 2018. http://anderbergonline.com/hiking-in-sand-dunes-atravelers-guid/.

"Led Lighting for Bedroom Platform Bed Design Plans Platform Beds May Be Simple in Design or Heavily Decorated Platform Bed Bedroom Note i Am Going to Use Cabinets Led Bedroom Wall Lights Uk." led lighting for bedroom platform bed design plans platform beds may be simple in design or heavily decorated platform bed bedroom note i am going to use cabinets led bedroom wall lights uk. Accessed September 11, 2018. http://papeur.com/. 
“Stock Video of Night Park - Benches and Lamps | 9462710." Shutterstock. Accessed September 10, 2018. https://www.shutterstock.com/video/clip9462710-night-park---benches-lamps.

“Sun-through-Trees-0385.Jpg (3648×2736).” Accessed September 10, 2018. https://cyclestuff.files.wordpress.com/2014/01/sun-through-trees-0385.jpg.

Lesser, Wendy. "Cloudy Thinking." Edited by Caryl Churchill, Richard Seyd, Tommy Tune, and David Hare. The Threepenny Review, no. 15 (1983): 27-28.

“QolorFLEX® 5-in-1 LED Tape.” Accessed April 4, 2019.

http://www.citytheatrical.com/Products/qolorflex-5-in-1-ledtape?dept=e71ecae2-cd2e-49f8-9565-f6a61de65f48\&subDept=ffa875fbb839-6b94-9d71-ff00001a956a\&pid=10a77cfb-b839-6b94-9d71ff00001a956a\#.

Rose, Brent. "180,000 Tiny People Are Holding Up This Floor." Gizmodo. Accessed April 4, 2019. https://gizmodo.com/180-000-tiny-people-are-holding-upthis-floor-5878454.

Keyssar, Helene. "The Dramas of Caryl Churchill: The Politics of Possibility." The Massachusetts Review 24, no. 1 (1983): 198-216.

Churchill, Caryl. Cloud 9, 1983. 
Appendix A: Light Plot 


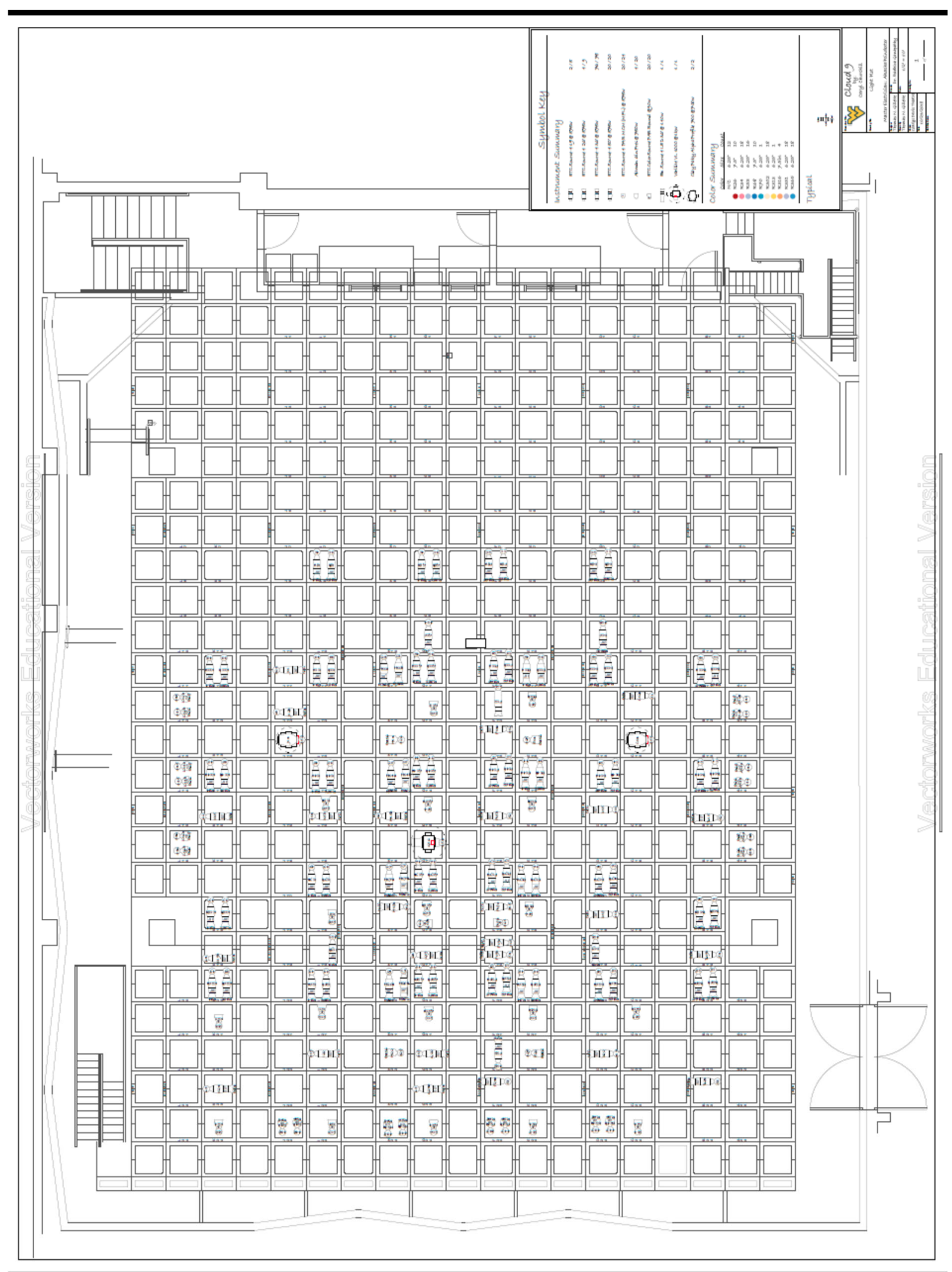




\section{Appendix B: Channel Hookup}

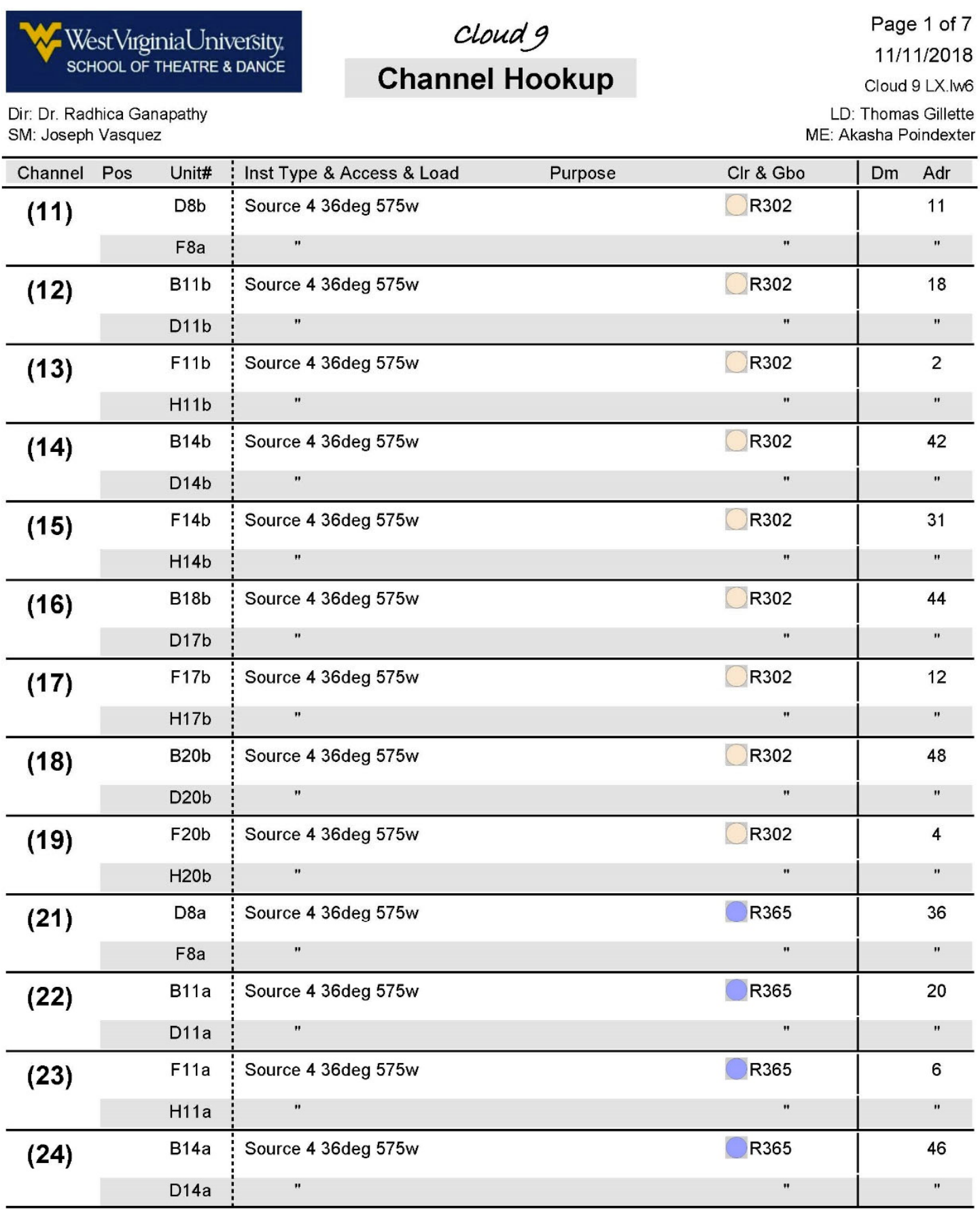




\begin{tabular}{|c|c|c|c|c|c|c|c|}
\hline \multicolumn{5}{|c|}{$\begin{array}{l}\text { West VirginiaUniversity, } \\
\text { schOOL OF THEATRE \& DANCE }\end{array}$} & \multicolumn{3}{|c|}{$\begin{array}{r}\text { Page } 2 \text { of } 7 \\
11 / 11 / 2018 \\
\text { Cloud } 9 \text { LX.Iw6 }\end{array}$} \\
\hline Channel & Pos & Unit\# & Inst Type \& Access \& Load & Purpose & Clr \& Gbo & $\mathrm{Dm}$ & Adr \\
\hline \multirow{2}{*}{ (25) } & & $\mathrm{F} 14 \mathrm{a}$ & Source 4 36deg $575 w$ & & R365 & & 32 \\
\hline & & $\mathrm{H} 14 \mathrm{a}$ & $"$ & & $"$ & & " \\
\hline \multirow[t]{2}{*}{ (26) } & & B18a & Source $436 \mathrm{deg} 575 w$ & & R365 & & 38 \\
\hline & & D17a & $"$ & & $"$ & & $"$ \\
\hline \multirow{2}{*}{ (27) } & & $\mathrm{F} 17 \mathrm{a}$ & Source 4 36deg $575 w$ & & R365 & & 10 \\
\hline & & $\mathrm{H} 17 \mathrm{a}$ & $"$ & & $"$ & & $"$ \\
\hline \multirow[t]{2}{*}{ (28) } & & $\mathrm{B} 20 \mathrm{a}$ & Source 4 36deg $575 w$ & & R365 & & 14 \\
\hline & & $\mathrm{D} 20 \mathrm{a}$ & $"$ & & $"$ & & $"$ \\
\hline \multirow[t]{2}{*}{ (29) } & & $\mathrm{F} 20 \mathrm{a}$ & Source 4 36deg $575 w$ & & R365 & & 8 \\
\hline & & $\mathrm{H} 20 \mathrm{a}$ & $"$ & & $"$ & & $"$ \\
\hline \multirow[t]{2}{*}{ (31) } & & $\mathrm{G} 8 \mathrm{~b}$ & Source 4 36deg $575 w$ & & R351 & & 25 \\
\hline & & $18 \mathrm{~b}$ & $"$ & & $"$ & & $"$ \\
\hline \multirow[t]{2}{*}{ (32) } & & $\mathrm{E} 11 \mathrm{~b}$ & Source 4 36deg $575 w$ & & R351 & & 73 \\
\hline & & G11b & $"$ & & $"$ & & $"$ \\
\hline \multirow[t]{2}{*}{ (33) } & & $\mathrm{I11b}$ & Source 4 36deg $575 w$ & & R351 & & 85 \\
\hline & & $\mathrm{K} 11 \mathrm{~b}$ & $"$ & & $"$ & & $"$ \\
\hline \multirow[t]{2}{*}{$(34)$} & & $\mathrm{E} 14 \mathrm{~b}$ & Source 4 36deg 575w & & R351 & & 77 \\
\hline & & G14b & $"$ & & $"$ & & " \\
\hline \multirow[t]{2}{*}{ (35) } & & $I 14 b$ & Source 4 36deg $575 w$ & & R351 & & 89 \\
\hline & & $\mathrm{K} 14 \mathrm{~b}$ & $"$ & & $"$ & & $"$ \\
\hline \multirow[t]{2}{*}{ (36) } & & $\mathrm{E} 17 \mathrm{~b}$ & Source 4 36deg 575w & & R351 & & 84 \\
\hline & & G17b & $"$ & & $"$ & & $"$ \\
\hline \multirow[t]{2}{*}{ (37) } & & $117 \mathrm{~b}$ & Source 4 36deg $575 w$ & & R351 & & 96 \\
\hline & & $\mathrm{K} 18 \mathrm{~b}$ & $"$ & & $"$ & & $"$ \\
\hline \multirow[t]{2}{*}{ (38) } & & $\mathrm{E} 20 \mathrm{~b}$ & Source 4 36deg $575 w$ & & R351 & & 81 \\
\hline & & G20b & $"$ & & $"$ & & $"$ \\
\hline \multirow[t]{2}{*}{ (39) } & & $\mathrm{I} 20 \mathrm{~b}$ & Source 4 36deg $575 w$ & & R351 & & 93 \\
\hline & & $\mathrm{K} 20 \mathrm{~b}$ & $"$ & & $"$ & & $"$ \\
\hline
\end{tabular}




\begin{tabular}{|c|c|c|c|c|c|c|c|}
\hline \multicolumn{5}{|c|}{$\begin{array}{l}\text { West VirginiaUniversity, } \\
\text { schOOL OF THEATRE \& DANCE }\end{array}$} & \multicolumn{3}{|c|}{$\begin{array}{l}\text { Page } 3 \text { of } \\
11 / 11 / 201 \\
\text { Cloud } 9 \text { LX.IV }\end{array}$} \\
\hline Channel & Pos & Unit\# & Inst Type \& Access \& Load & Purpose & Clr \& Gbo & Dm & Adr \\
\hline \multirow[t]{2}{*}{ (41) } & & G8a & Source 4 36deg $575 w$ & & R34 & & 26 \\
\hline & & $18 a$ & $"$ & & $"$ & & $"$ \\
\hline \multirow[t]{2}{*}{ (42) } & & E11a & Source 4 36deg $575 w$ & & R34 & & 74 \\
\hline & & G11a & $"$ & & $"$ & & $"$ \\
\hline \multirow[t]{2}{*}{ (43) } & & $111 \mathrm{a}$ & Source 436 deg $575 w$ & & R34 & & 86 \\
\hline & & K11a & $"$ & & $"$ & & $"$ \\
\hline \multirow[t]{2}{*}{ (44) } & & $\mathrm{E} 14 \mathrm{a}$ & Source 4 36deg $575 w$ & & R34 & & 78 \\
\hline & & G14a & $"$ & & $"$ & & $"$ \\
\hline \multirow{2}{*}{ (45) } & & $\mathrm{I14a}$ & Source 4 36deg $575 w$ & & R34 & & 90 \\
\hline & & $\mathrm{K} 14 \mathrm{a}$ & $"$ & & $"$ & & $"$ \\
\hline \multirow[t]{2}{*}{$(46)$} & & $\mathrm{E} 17 \mathrm{a}$ & Source 4 36deg $575 w$ & & R34 & & 83 \\
\hline & & G17a & $"$ & & $"$ & & $"$ \\
\hline \multirow[t]{2}{*}{ (47) } & & $\mathrm{I17a}$ & Source 4 36deg $575 w$ & & R34 & & 95 \\
\hline & & $\mathrm{K} 18 \mathrm{a}$ & " & & $"$ & & $"$ \\
\hline \multirow[t]{2}{*}{$(48)$} & & E20a & Source 4 36deg $575 w$ & & R34 & & 82 \\
\hline & & G20a & $"$ & & $"$ & & $"$ \\
\hline \multirow[t]{2}{*}{ (49) } & & $120 \mathrm{a}$ & Source 436 deg $575 w$ & & R34 & & 94 \\
\hline & & $\mathrm{K} 20 \mathrm{a}$ & $"$ & & $"$ & & $"$ \\
\hline (51) & & $\mathrm{C} 12 \mathrm{a}$ & Source $450 \mathrm{deg} 750 \mathrm{w}$ & & $\begin{array}{l}\text { R53, T: } \\
\text { R79082 }\end{array}$ & & 22 \\
\hline \multirow[t]{2}{*}{$(52)$} & & B15 & Source 450 deg $750 w$ & & $\begin{array}{l}\text { R53, T: } \\
\text { R79082 }\end{array}$ & & 28 \\
\hline & & $\mathrm{F} 15 \mathrm{~b}$ & $"$ & & $"$ & & $"$ \\
\hline \multirow[t]{2}{*}{ (53) } & & B19b & Source $450 \mathrm{deg} 750 \mathrm{w}$ & & $\begin{array}{l}\text { R53, T: } \\
\text { R79082 }\end{array}$ & & 30 \\
\hline & & $\mathrm{F} 19 \mathrm{~b}$ & $"$ & & $"$ & & $"$ \\
\hline \multirow[t]{2}{*}{ (54) } & & B23 & Source $450 \mathrm{deg} 750 w$ & & $\begin{array}{l}\text { R53, T: } \\
\text { R79082 }\end{array}$ & & 40 \\
\hline & & $\mathrm{F} 23 \mathrm{a}$ & $"$ & & $"$ & & $"$ \\
\hline (61) & & $\mathrm{J} 12 \mathrm{~b}$ & Source $450 \mathrm{deg} 750 w$ & & $\begin{array}{l}\text { R53, T: } \\
\text { R77597 }\end{array}$ & & 9 \\
\hline
\end{tabular}




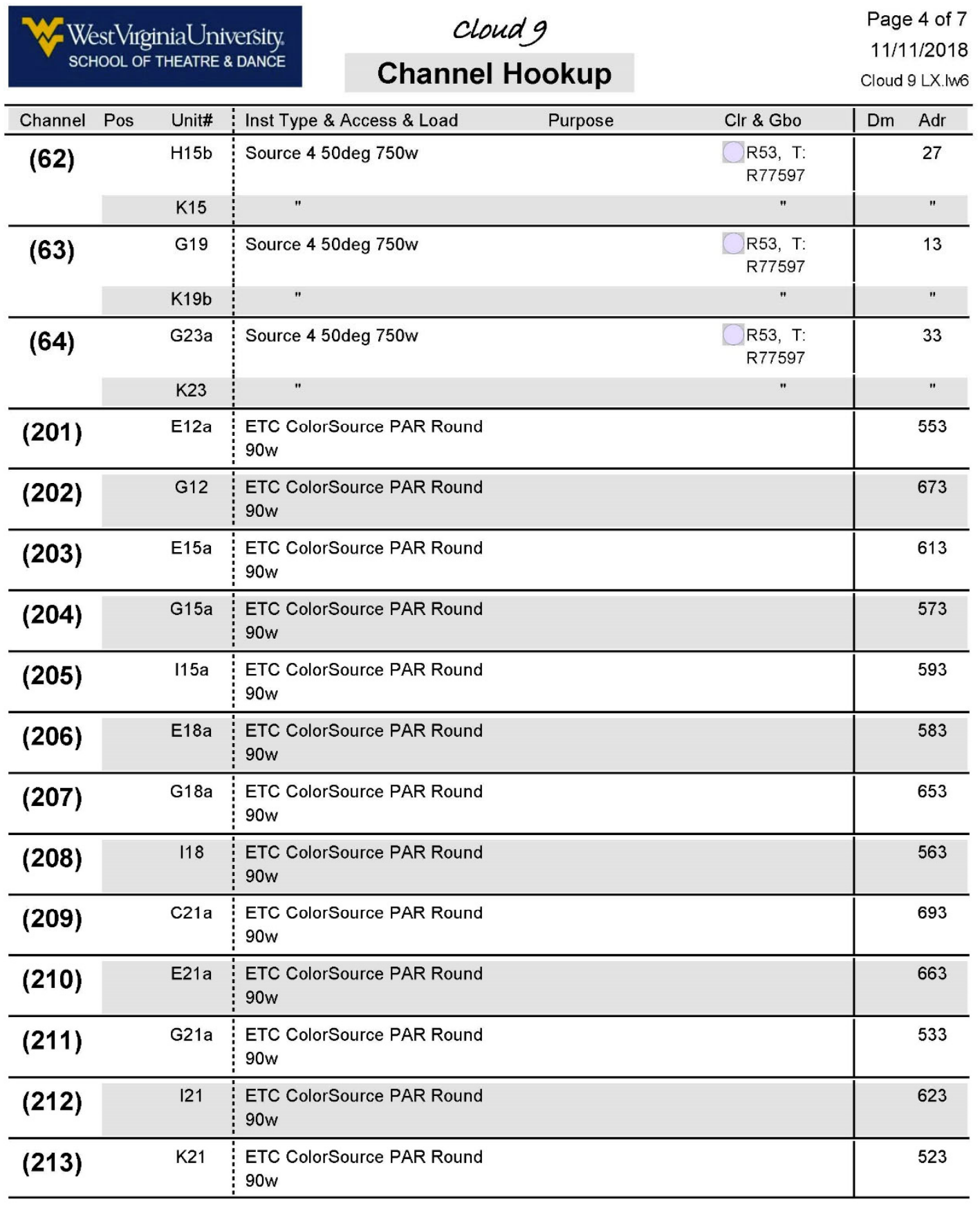




\begin{tabular}{|c|c|c|c|c|c|c|c|}
\hline \multicolumn{5}{|c|}{$\begin{array}{l}\text { West VirginiaUniversity. } \\
\text { SCHOOL OF THEATRE \& DANCE }\end{array}$} & \multicolumn{3}{|c|}{$\begin{array}{r}\text { Page } 5 \text { of } 7 \\
11 / 11 / 2018 \\
\text { Cloud } 9 \text { LX.Iw6 }\end{array}$} \\
\hline Channel & Pos & Unit\# & Inst Type \& Access \& Load & Purpose & Clr \& Gbo & $\mathrm{Dm}$ & Adr \\
\hline$(214)$ & & $\mathrm{C} 24$ & $\begin{array}{l}\text { ETC ColorSource PAR Round } \\
90 \mathrm{w}\end{array}$ & & & & 603 \\
\hline$(215)$ & & E24 & $\begin{array}{l}\text { ETC ColorSource PAR Round } \\
90 \mathrm{w}\end{array}$ & & & & 513 \\
\hline (216) & & G24 & $\begin{array}{l}\text { ETC ColorSource PAR Round } \\
90 \mathrm{w}\end{array}$ & & & & 543 \\
\hline$(217)$ & & 124 & $\begin{array}{l}\text { ETC ColorSource PAR Round } \\
90 \mathrm{w}\end{array}$ & & & & 703 \\
\hline (218) & & $\mathrm{K} 24$ & $\begin{array}{l}\text { ETC ColorSource PAR Round } \\
90 \mathrm{w}\end{array}$ & & & & 633 \\
\hline (221) & & $\mathrm{F} 12$ & Etc Source 4 LED $36^{\circ} 140 \mathrm{w}$ & & & & 913 \\
\hline$(411)$ & & D15 & Source $450 \mathrm{deg} 750 \mathrm{w}$ & Union Jack & $\mathrm{N} / \mathrm{C}$ & & 79 \\
\hline$(412)$ & & $\mathrm{F} 13 \mathrm{a}$ & Source $450 \mathrm{deg} 750 \mathrm{w}$ & Union Jack & $\mathrm{N} / \mathrm{C}$ & & 75 \\
\hline$(413)$ & & $\mathrm{I15b}$ & Source $450 \mathrm{deg} 750 \mathrm{w}$ & Union Jack & $\mathrm{N} / \mathrm{C}$ & & 91 \\
\hline$(414)$ & & D18 & Source 4 36deg $575 w$ & Union Jack & $\mathrm{N} / \mathrm{C}$ & & 16 \\
\hline \multirow{2}{*}{$(415)$} & & F18a & Source 4 36deg $575 w$ & Union Jack & $\mathrm{N} / \mathrm{C}$ & & 24 \\
\hline & & $\mathrm{F} 19 \mathrm{a}$ & $"$ & $"$ & $"$ & & $"$ \\
\hline$(416)$ & & $\mathrm{H} 18 \mathrm{a}$ & Source 436 deg $575 w$ & Union Jack & $\mathrm{N} / \mathrm{C}$ & & 1 \\
\hline$(417)$ & & $\mathrm{D} 22$ & Source $450 \mathrm{deg} 750 \mathrm{w}$ & Union Jack & $\mathrm{N} / \mathrm{C}$ & & 80 \\
\hline (418) & & G22 & Source $450 \mathrm{deg} 750 \mathrm{w}$ & Union Jack & $\mathrm{N} / \mathrm{C}$ & & 3 \\
\hline$(419)$ & & 122 & Source 450 deg $750 w$ & Union Jack & $\mathrm{N} / \mathrm{C}$ & & 7 \\
\hline \multirow[t]{2}{*}{$(421)$} & & D19 & Source 4 19deg $575 w$ & Act 2 Signs & R53 & & 15 \\
\hline & & $119 b$ & $"$ & $"$ & $"$ & & $"$ \\
\hline$(422)$ & & $\mathrm{F} 22$ & Source 4 26deg 575w & Soldier Sp. & R70 & & 11 \\
\hline (423) & & D10 & Source 426 deg $575 w$ & Edward Sp. & R313 & & 87 \\
\hline \multirow[t]{2}{*}{$(424)$} & & G10 & Source 4 26deg $575 w$ & $\begin{array}{l}\text { Act } 2 \text { Transition } \\
\text { Sign Sp. }\end{array}$ & $\mathrm{N} / \mathrm{C}$ & & 17 \\
\hline & & $\mathrm{J} 11$ & $"$ & $"$ & $"$ & & $"$ \\
\hline$(425)$ & & E13 & Altman 6in Fres $750 w$ & Park Lights & R316 & & 76 \\
\hline
\end{tabular}




\begin{tabular}{|c|c|c|c|c|c|c|c|}
\hline \multicolumn{3}{|c|}{$\begin{array}{l}\text { West VirginiaUniversity; } \\
\text { schoOL OF THEATRE \& DANCE }\end{array}$} & \multicolumn{2}{|c|}{ Channel Hookup } & \multirow[b]{2}{*}{ Clr \& Gbo } & \multicolumn{2}{|c|}{$\begin{array}{r}\text { Page } 6 \text { of } 7 \\
11 / 11 / 2018 \\
\text { Cloud } 9 \text { LX.Iw6 }\end{array}$} \\
\hline Channel & Pos & Unit\# & Inst Type \& Access \& Load & Purpose & & $\mathrm{Dm}$ & Adr \\
\hline$(426)$ & & $\mathrm{H} 13$ & Altman 6in Fres $750 w$ & Park Lights & R316 & & 5 \\
\hline$(427)$ & & E22 & Altman 6 in Fres $750 w$ & Park Lights & R316 & & 45 \\
\hline$(428)$ & & $\mathrm{H} 22$ & Altman 6 in Fres $750 w$ & Park Lights & R316 & & 47 \\
\hline$(431)$ & & $\mathrm{A} 12 \mathrm{a}$ & S4 PAR MFL 575w & & R68 & & 60 \\
\hline$(432)$ & & A14a & S4 PAR MFL 575w & & R68 & & 50 \\
\hline$(433)$ & & A16a & S4 PAR MFL 575w & & R68 & & 54 \\
\hline$(434)$ & & L12a & S4 PAR MFL 575w & & R68 & & 41 \\
\hline$(435)$ & & L14a & S4 PAR MFL 575w & & R68 & & 53 \\
\hline (436) & & L16a & S4 PAR MFL 575w & & R68 & & 55 \\
\hline \multirow[t]{2}{*}{$(437)$} & & $\mathrm{D} 24 \mathrm{a}$ & S4 PAR MFL 575w & & R68 & & 35 \\
\hline & & F24a & $"$ & & $"$ & & $"$ \\
\hline \multirow[t]{2}{*}{ (438) } & & $\mathrm{H} 24 \mathrm{a}$ & S4 PAR MFL 575w & & R68 & & 37 \\
\hline & & $\mathrm{J} 24 \mathrm{a}$ & $"$ & & $"$ & & $"$ \\
\hline$(441)$ & & $A 12 b$ & S4 PAR MFL 575w & & $\mathrm{R} 26$ & & 58 \\
\hline (442) & & $A 14 b$ & S4 PAR MFL 575w & & R26 & & 52 \\
\hline (443) & & $\mathrm{A} 16 \mathrm{~b}$ & S4 PAR MFL 575w & & R26 & & 56 \\
\hline (444) & & $\mathrm{L} 12 \mathrm{~b}$ & S4 PAR MFL 575w & & R26 & & 43 \\
\hline$(445)$ & & L14b & S4 PAR MFL 575w & & R26 & & 57 \\
\hline (446) & & L16b & S4 PAR MFL 575w & & R26 & & 59 \\
\hline \multirow[t]{2}{*}{ (447) } & & D24b & S4 PAR MFL 575w & & R26 & & 29 \\
\hline & & $\mathrm{F} 24 \mathrm{~b}$ & $"$ & & $"$ & & $"$ \\
\hline \multirow[t]{2}{*}{ (448) } & & $\mathrm{H} 24 \mathrm{~b}$ & S4 PAR MFL 575w & & R26 & & 39 \\
\hline & & $\mathrm{J} 24 \mathrm{~b}$ & $"$ & & $"$ & & $"$ \\
\hline (451) & & $\mathrm{C} 13$ & $\begin{array}{l}\text { Clay Paky Alpha Profile } 700 \\
700 w\end{array}$ & & & & 813 \\
\hline
\end{tabular}




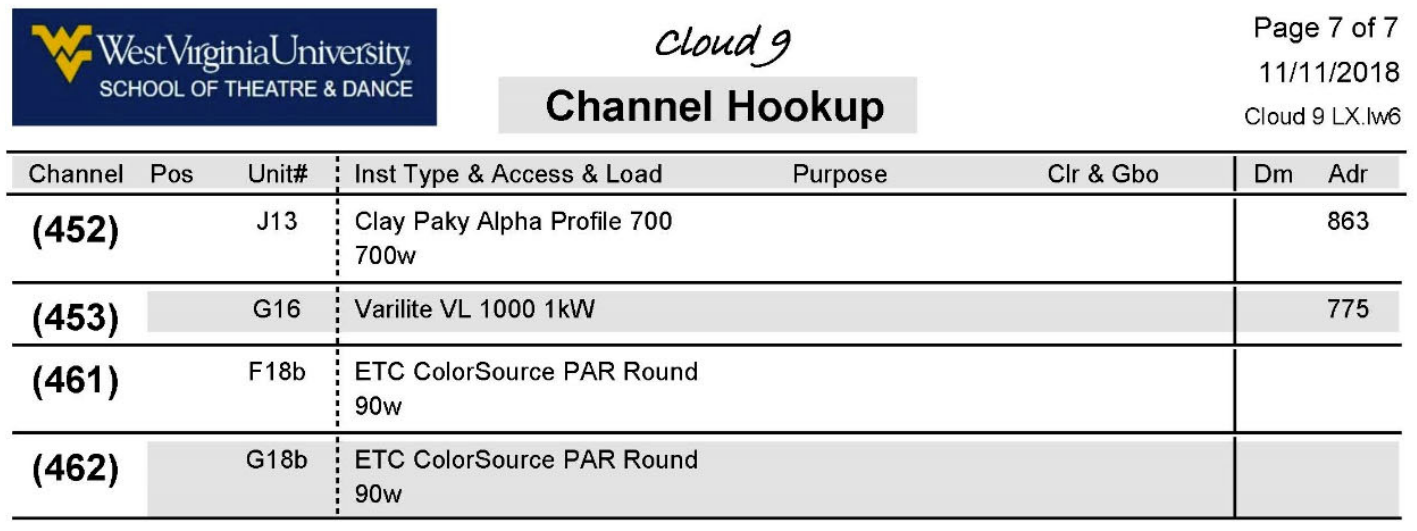




\section{Appendix C: Budget}

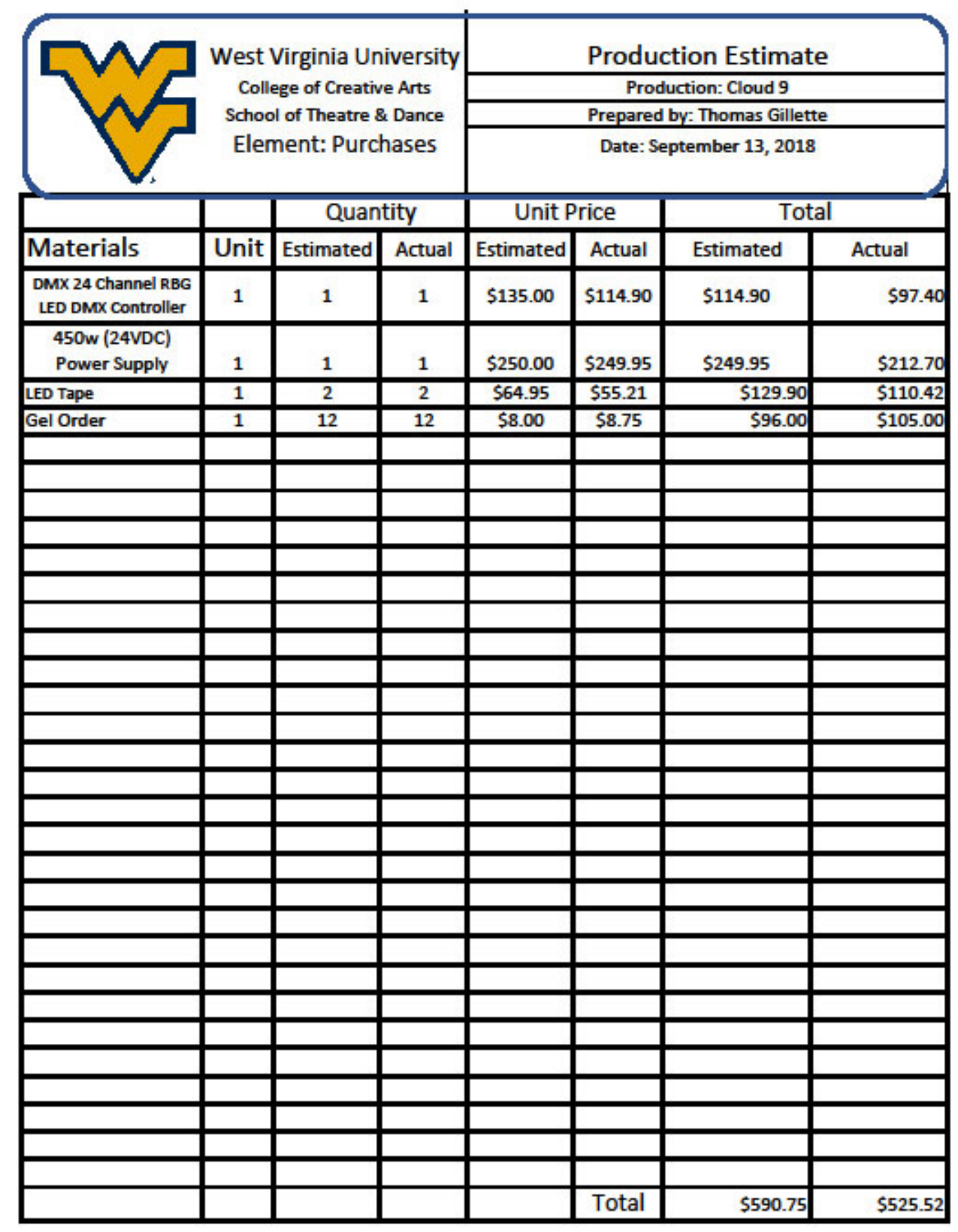




\section{Appendix D: Magic Sheet (EOS)}

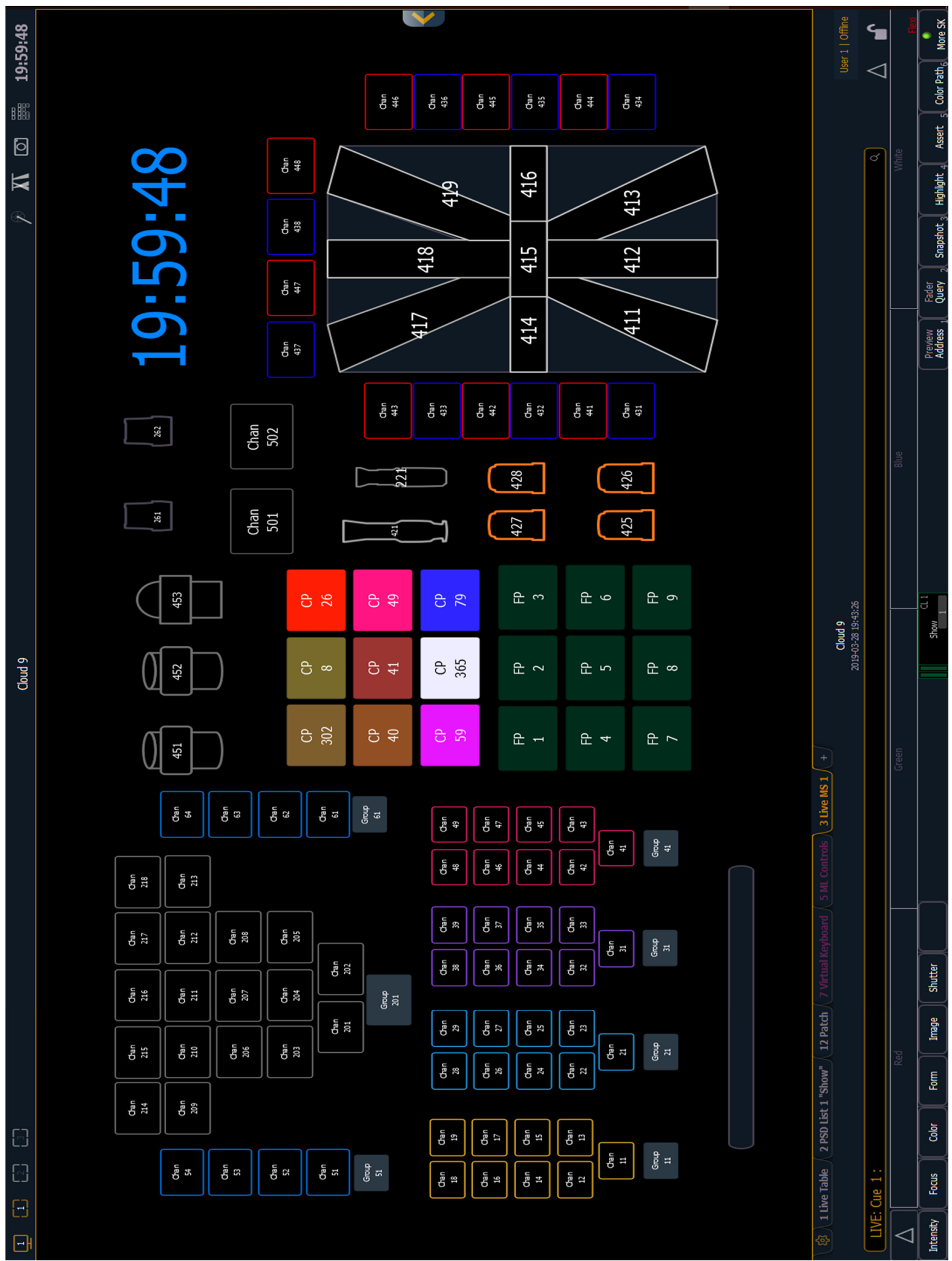




\section{Appendix E: Color Key}
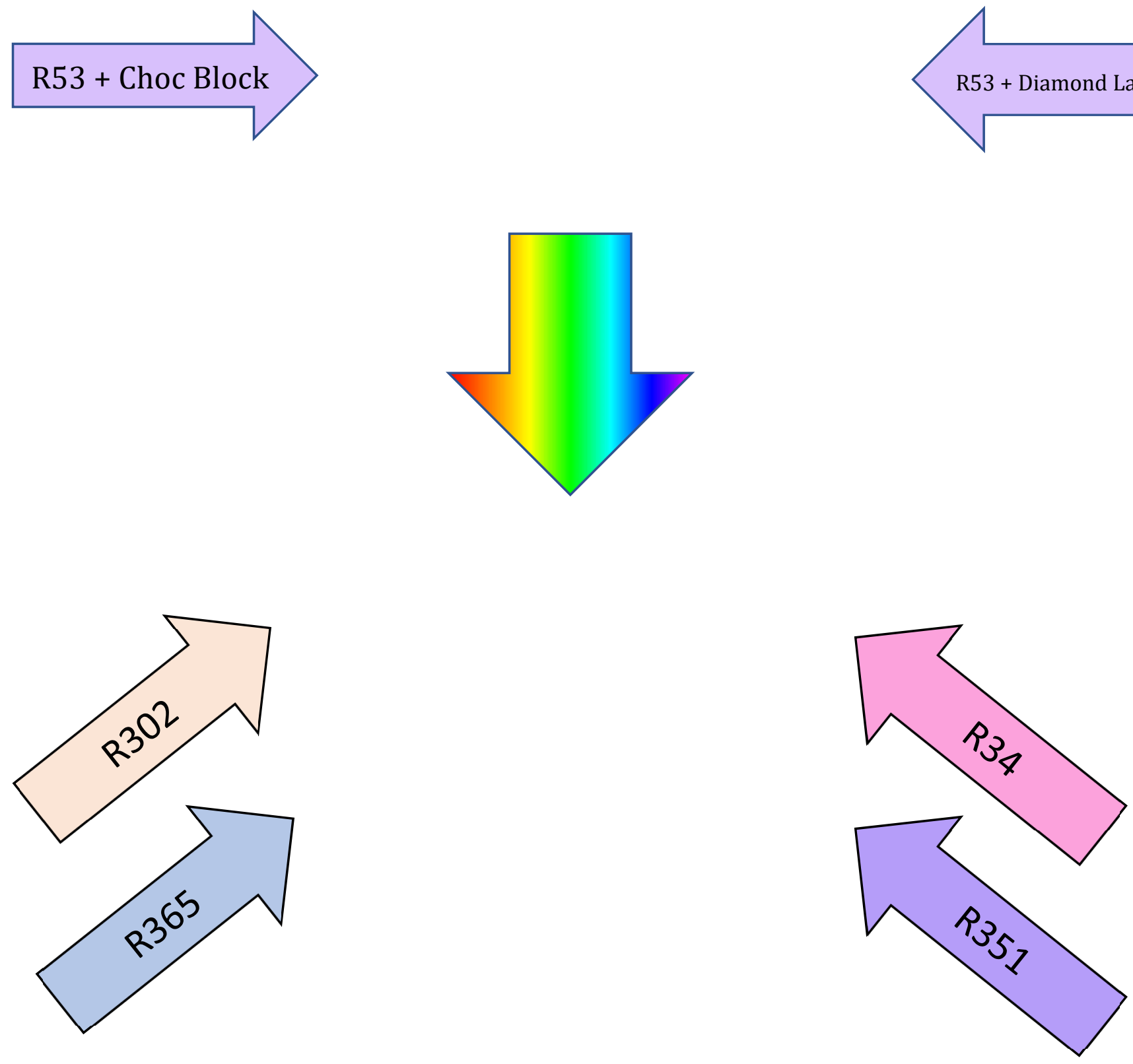


\section{Appendix F: Cue Synopsis}

\begin{tabular}{|c|c|c|c|c|}
\hline \multicolumn{2}{|c|}{$\begin{array}{l}\text { West VirginiaUniversity } \\
\text { sci IOOL Or TIICATRC \& DANCE }\end{array}$} & \multirow{2}{*}{$\begin{array}{l}\text { Cloud } 9 \\
\text { Cue List }\end{array}$} & \multicolumn{2}{|c|}{$\begin{array}{l}\text { LD: Thomas Gillette } \\
\text { ME: Akasha Poindexter } \\
\text { SM: Joseph Vasquez } \\
\text { DIR: Radhica Ganapathy }\end{array}$} \\
\hline Cue \# & Onstage & & Time & Page \# \\
\hline 1 & Preshow & House @ FL & 4 & 5 \\
\hline 2 & Preshow Announcement & House @ 50\% & 4 & 5 \\
\hline 3 & Conclusion of Announcement & House Out & 4 & 5 \\
\hline 5 & w/ drums & Lights Up (intro of characters) & 4 & 5 \\
\hline 10 & w/ sound (photograph) & Flash effect & 0 & 6 \\
\hline 15 & w/ sound (photograph) & Flash effect & 0 & 6 \\
\hline 20 & w/ sound (photograph) & Flash effect & 0 & 6 \\
\hline 25 & w/ sound (photograph) & Flash effect & 0 & 7 \\
\hline 30 & as everyone except Betty \& Clive leave & Reality & 4 & 7 \\
\hline 35 & Betty: "It's about Joshua" & Begin transition to dusk & $10: 00$ & 9 \\
\hline 40 & End Scene 1 & Transition night to day & 8 & 20 \\
\hline 45 & playing catch w/ edward & clouds & 8 & 24 \\
\hline 50 & Joshua sings... & Fade down & 5 & 34 \\
\hline 55 & after joshua exits & new scene & 5 & 34 \\
\hline 60 & betty exits & change TOD & 5 & 41 \\
\hline 65 & 14 ends & change TOD & 5 & 50 \\
\hline 70 & Joshua aims at Clive & Sp.'s on Joshua \& Clive & 1 & 54 \\
\hline 75 & & $\mathrm{~B} / \mathrm{O}$ & 0 & 54 \\
\hline 80 & 1 & Intermission & 3 & 54 \\
\hline 85 & & House @ 50\% & 3 & 54 \\
\hline 90 & & copy of cue 70 & 3 & 54 \\
\hline 95 & Crowd converges on Matt (DSL) & Isolate DSL & 20 & 54 \\
\hline 100 & Matt Leaves stone & Create "limbo" & 4 & 54 \\
\hline 105 & music starts & & & 54 \\
\hline 110 & start dancing on platform & & & 54 \\
\hline 115 & dancers circle platform & & & 54 \\
\hline 120 & just before Liam jumps into arms & Union Jack Reveal & & 54 \\
\hline 125 & Lift & & & 54 \\
\hline 130 & "we gave ourselves one more chance...." & & & 54 \\
\hline 135 & Music fades out & & & 54 \\
\hline 140 & radio Announcement & Slow fade to scene (winter) & & 55 \\
\hline 145 & Lin \& Vic leave & Shift to Spring & 3 & 65 \\
\hline 150 & Vic \& Edward Leave & Shift to night @ the park & 3 & 80 \\
\hline 155 & Edward:"tear me to pieces..." & US park light slight flicker & & 82 \\
\hline 160 & Vic: "Who is it?" & Light up Soldier & 2 & 84 \\
\hline 165 & Soldier Leaves & Sp. Out & 2 & 85 \\
\hline 170 & Edward leaves & Shift to Sunny Afternoon & 4 & 86 \\
\hline 175 & Edward \& Betty Embrace & $B / O$ & 3 & 97 \\
\hline & & & & \\
\hline & & & & \\
\hline & & & & \\
\hline
\end{tabular}

Page 1 of 1 


\section{Appendix G: Additional Research Images}

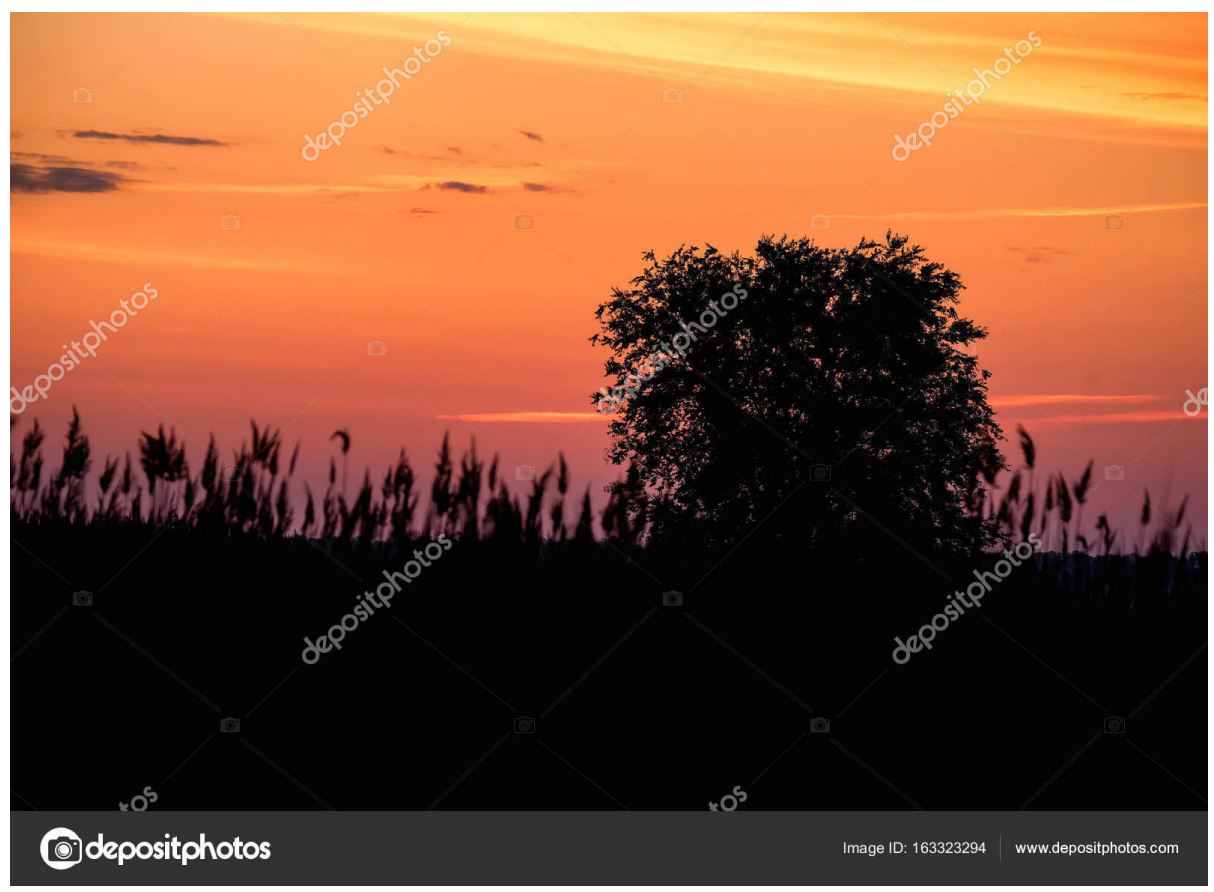

Used as reference when choosing Act I colors.

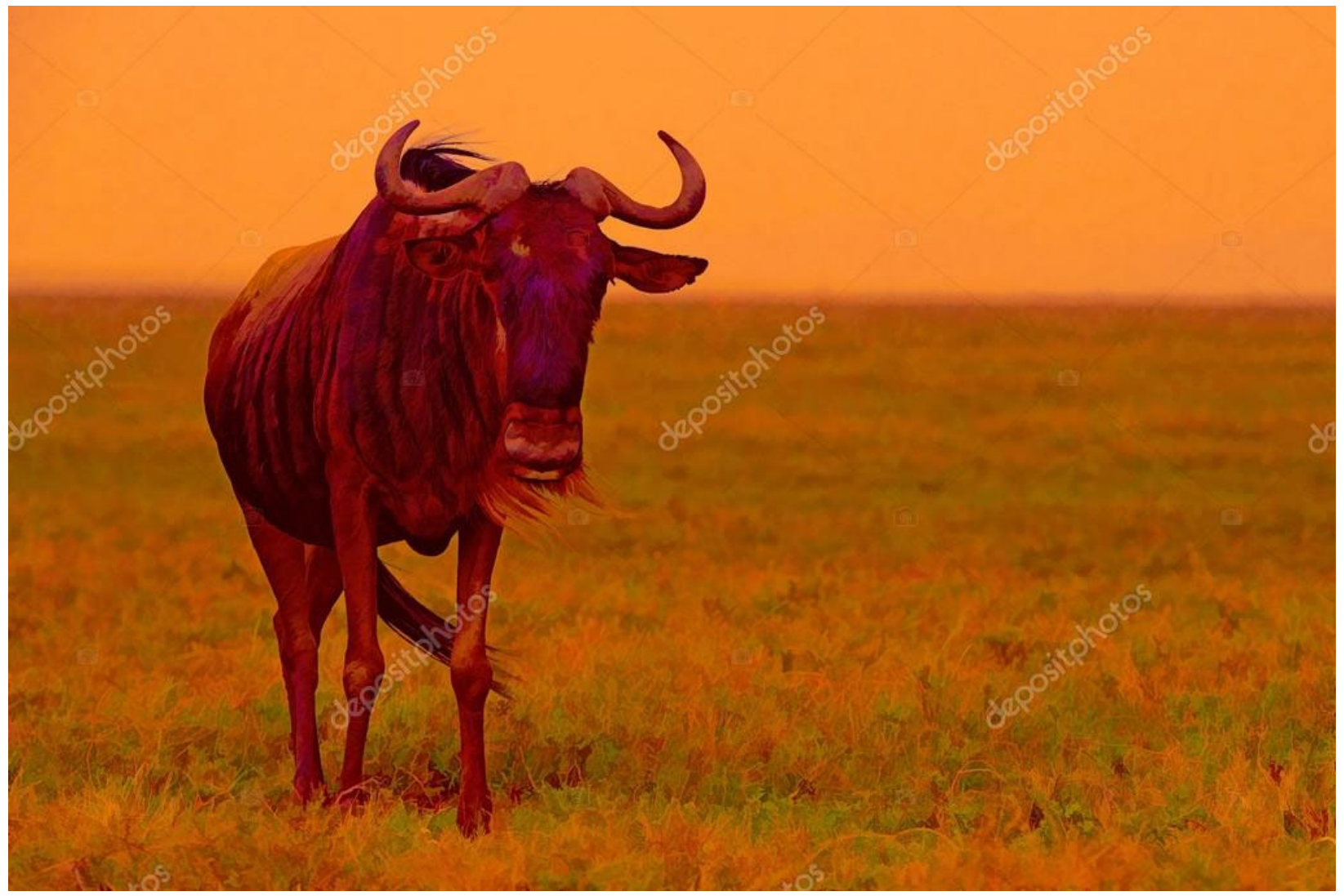

More Act I color research. 


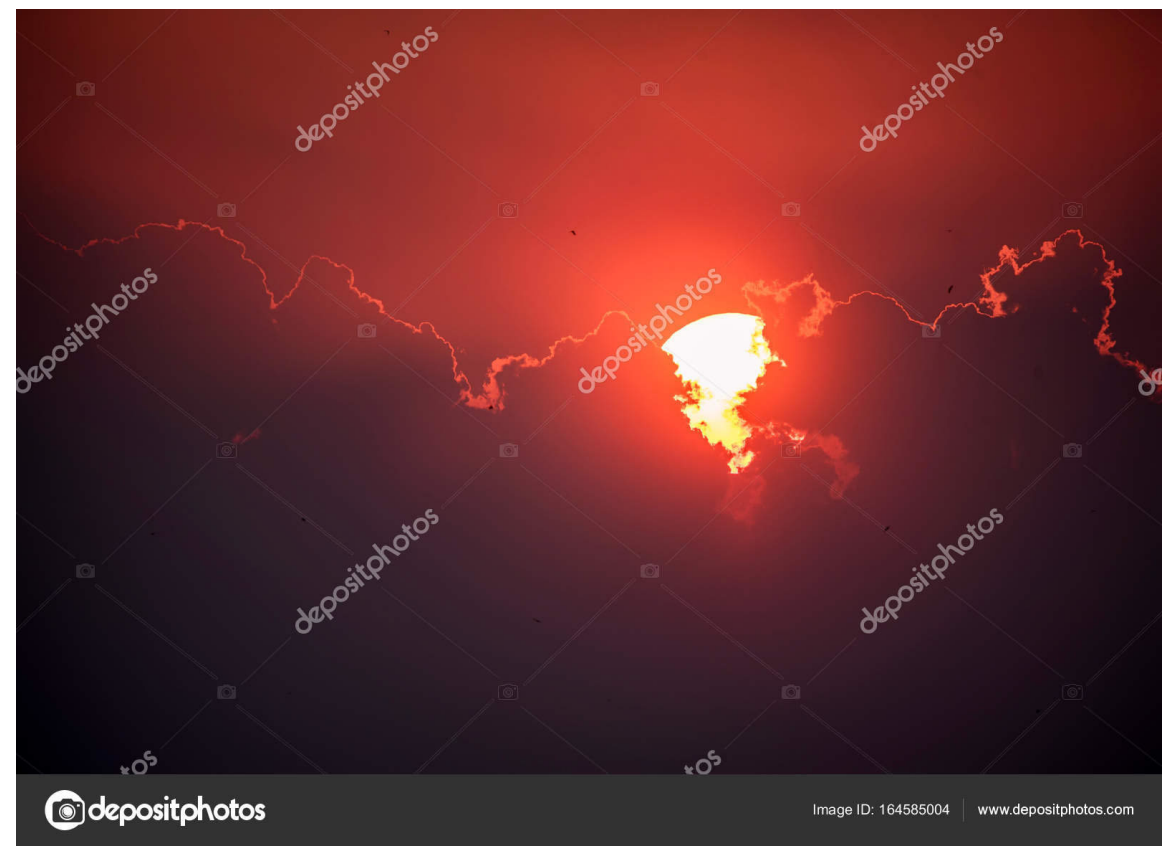

Act I color research

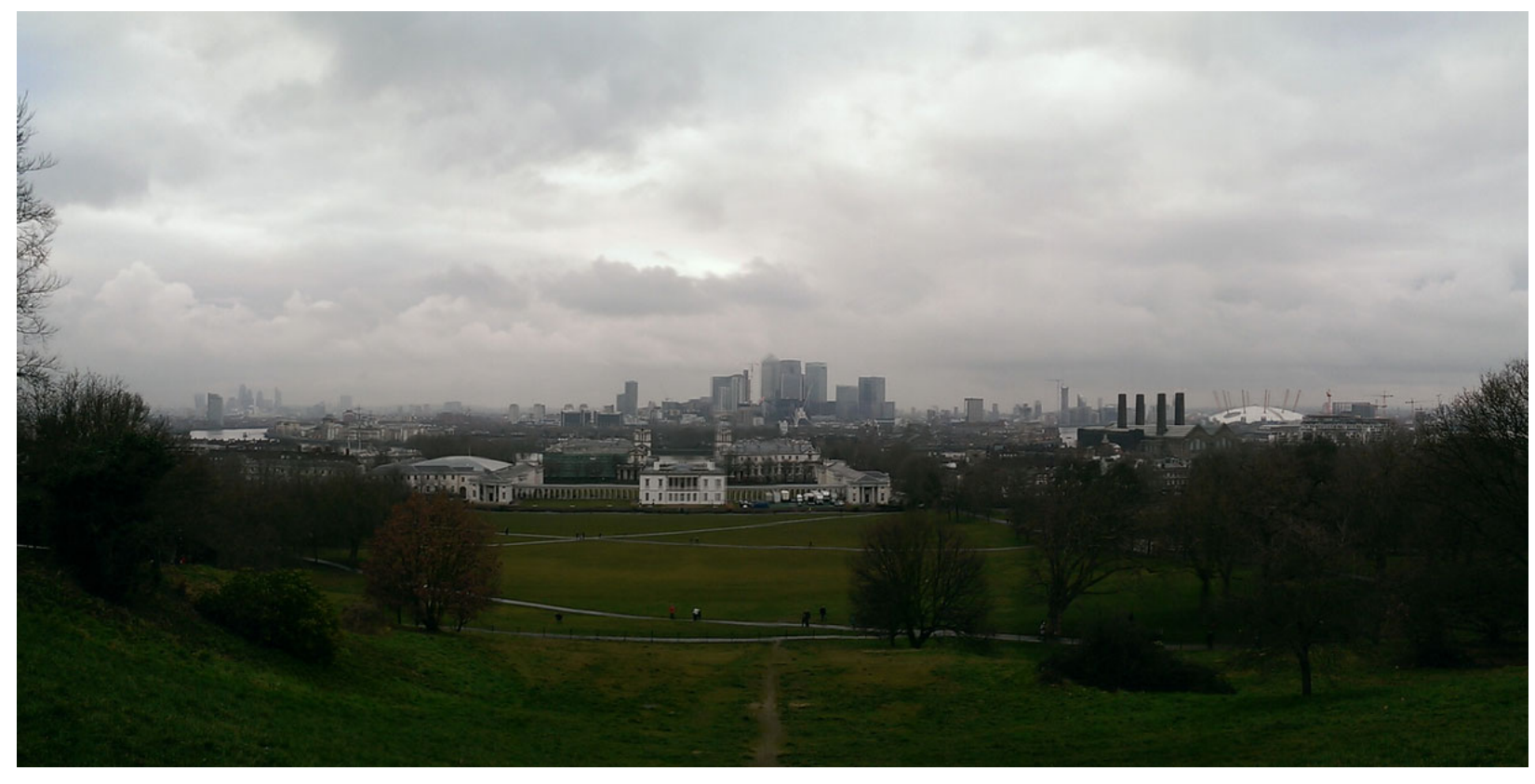

Act II Research 


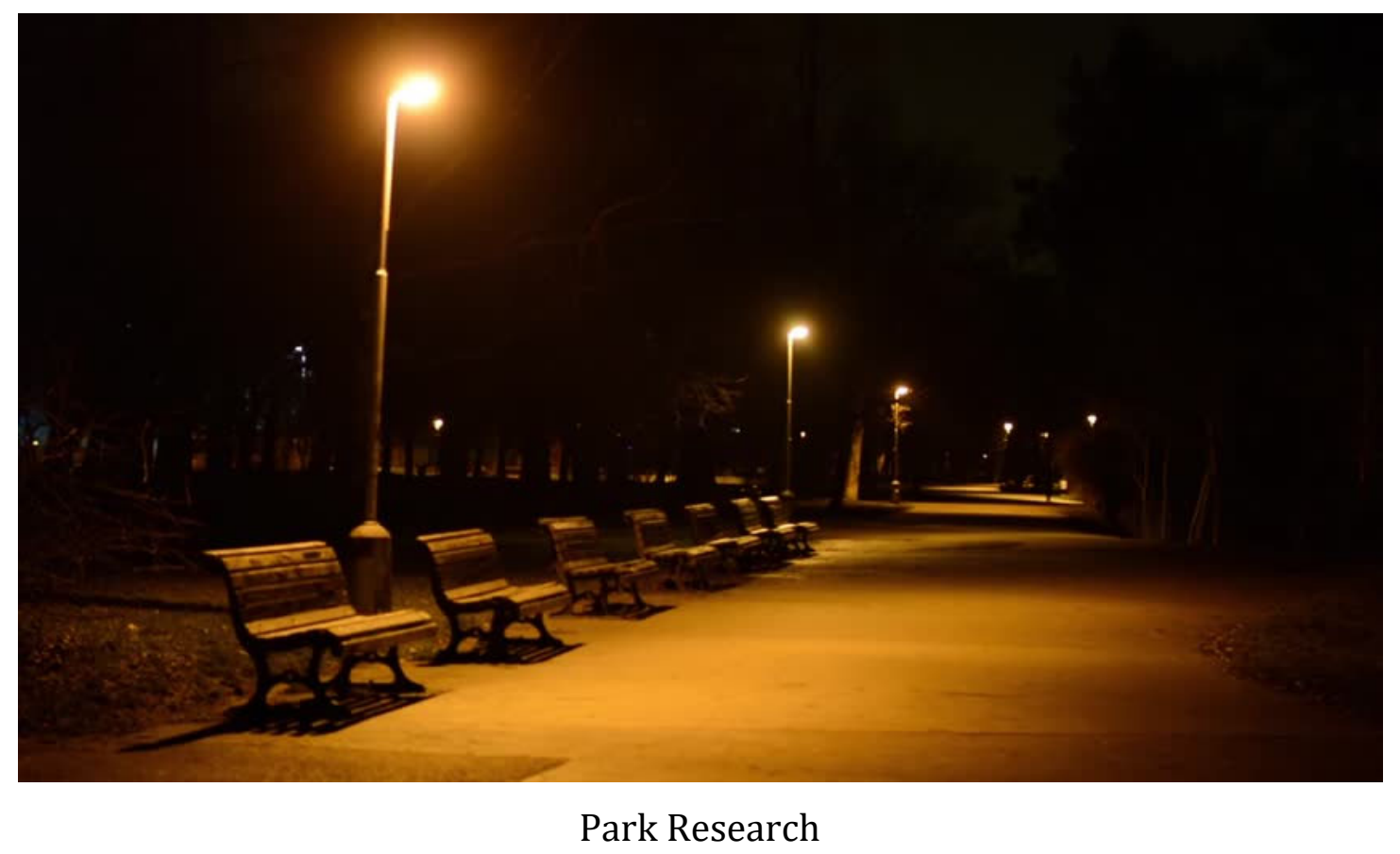




\section{Appendix H: Additional Production Photos}

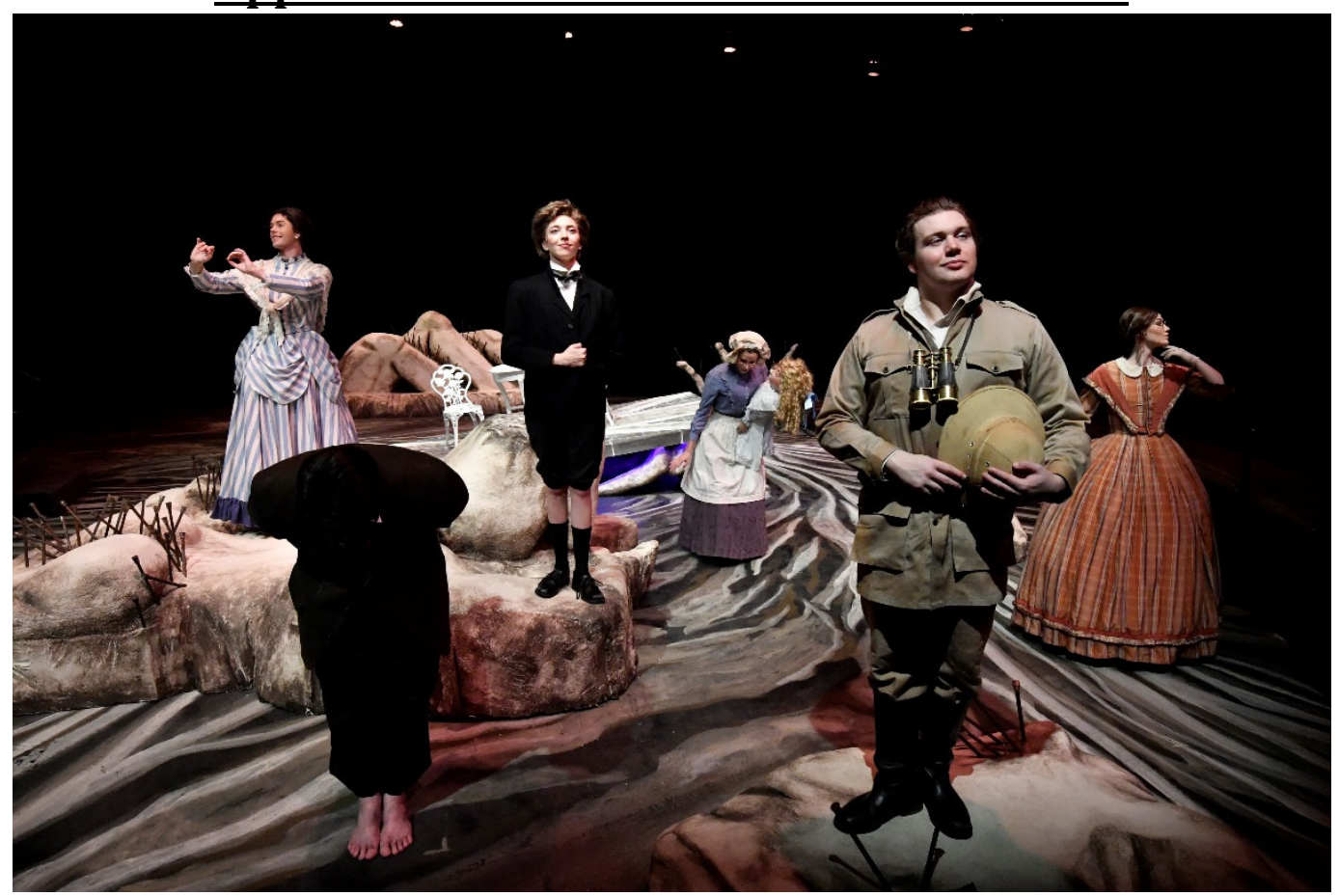

Act I Scene I “Family Portrait”

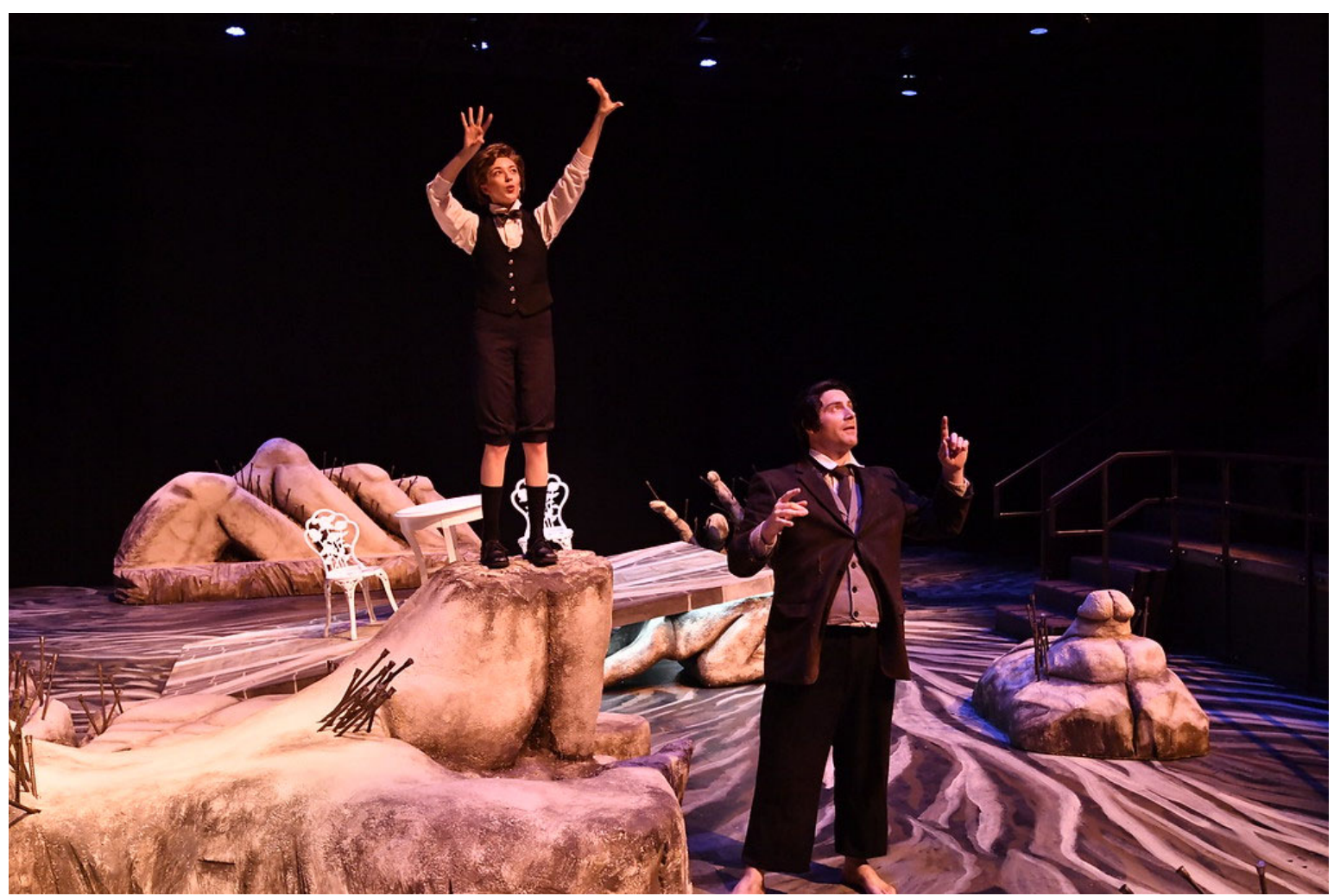

Act I Scene 4 


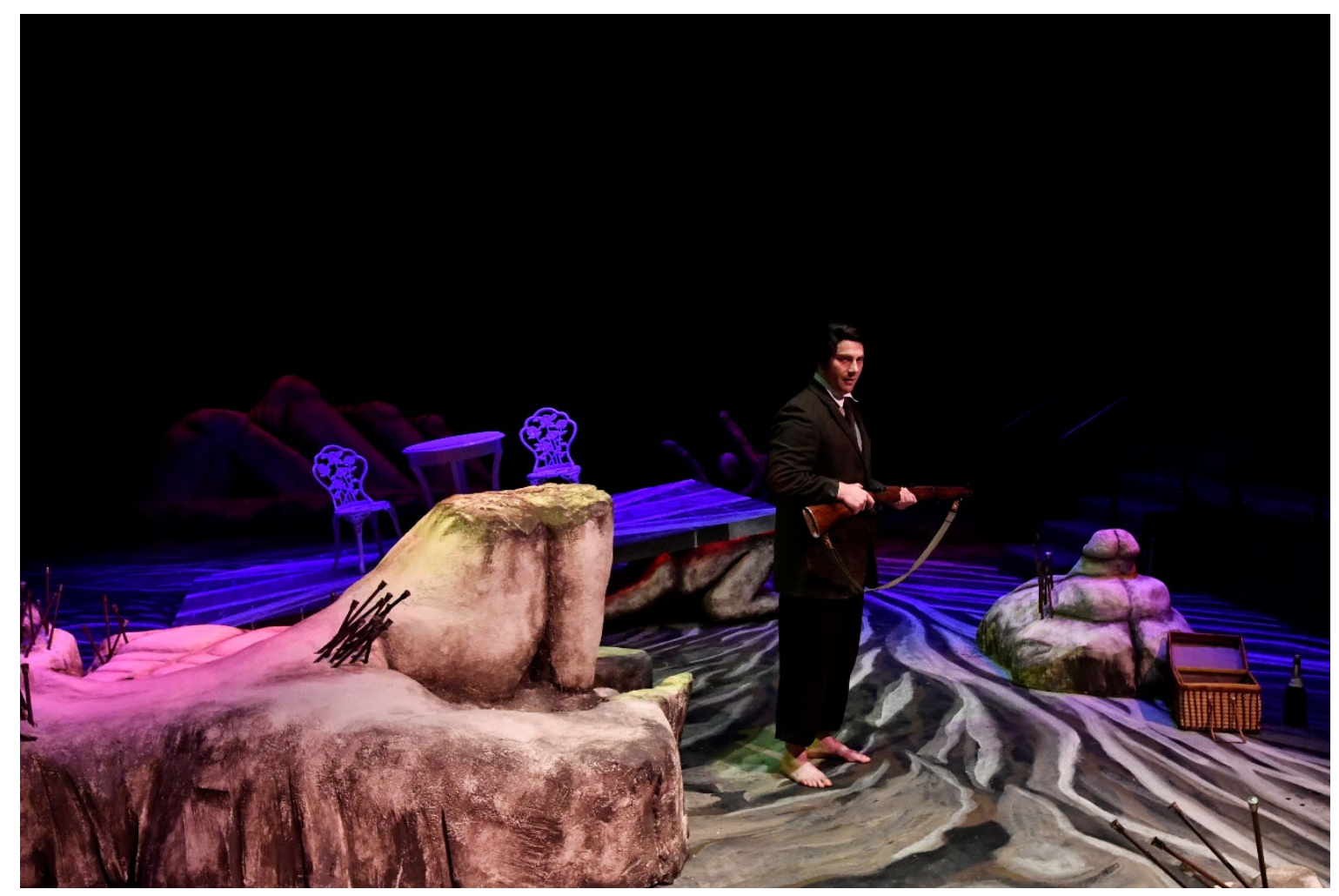

\section{Act I Scene 2}

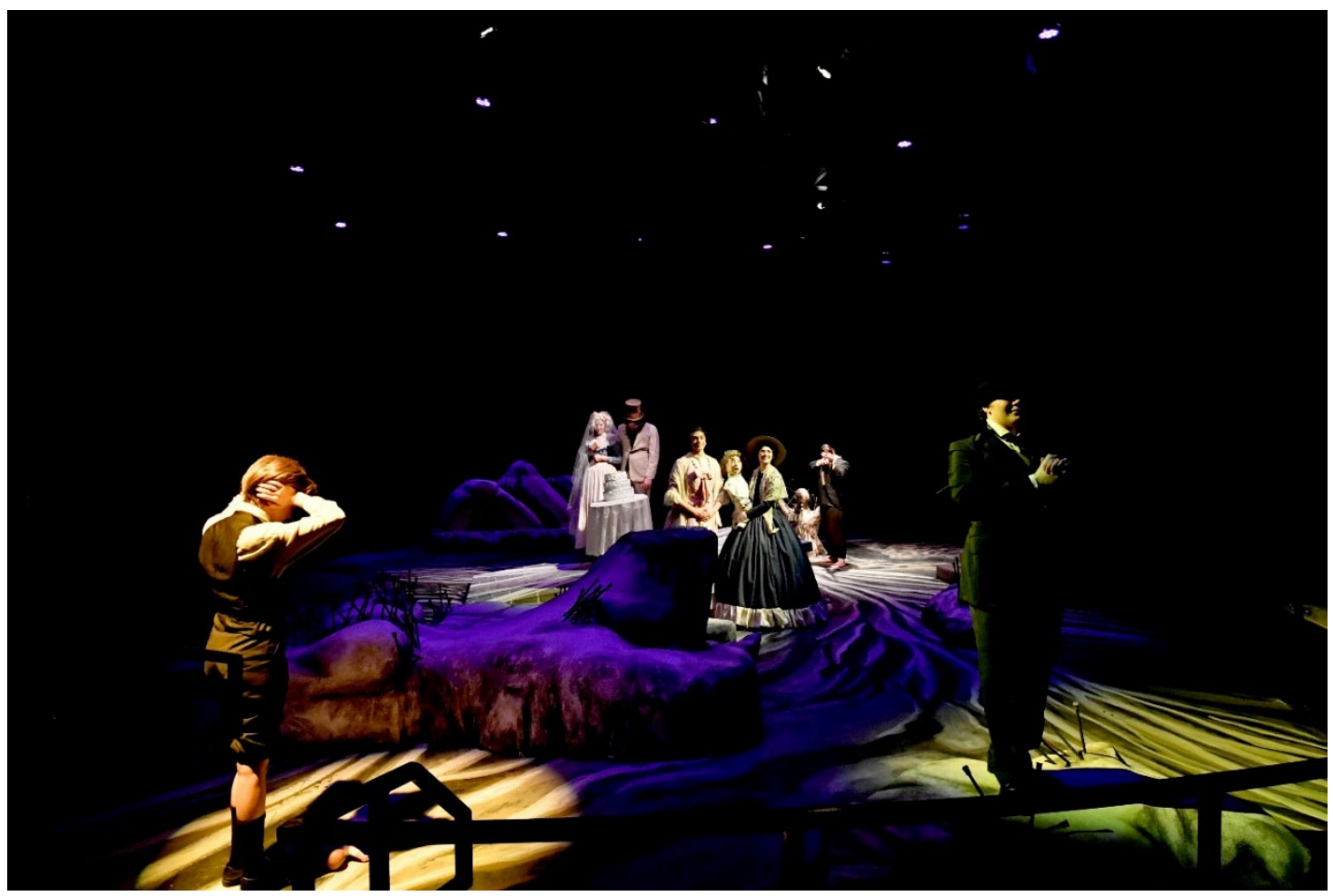

End of Act I 
Top of Act II Transition

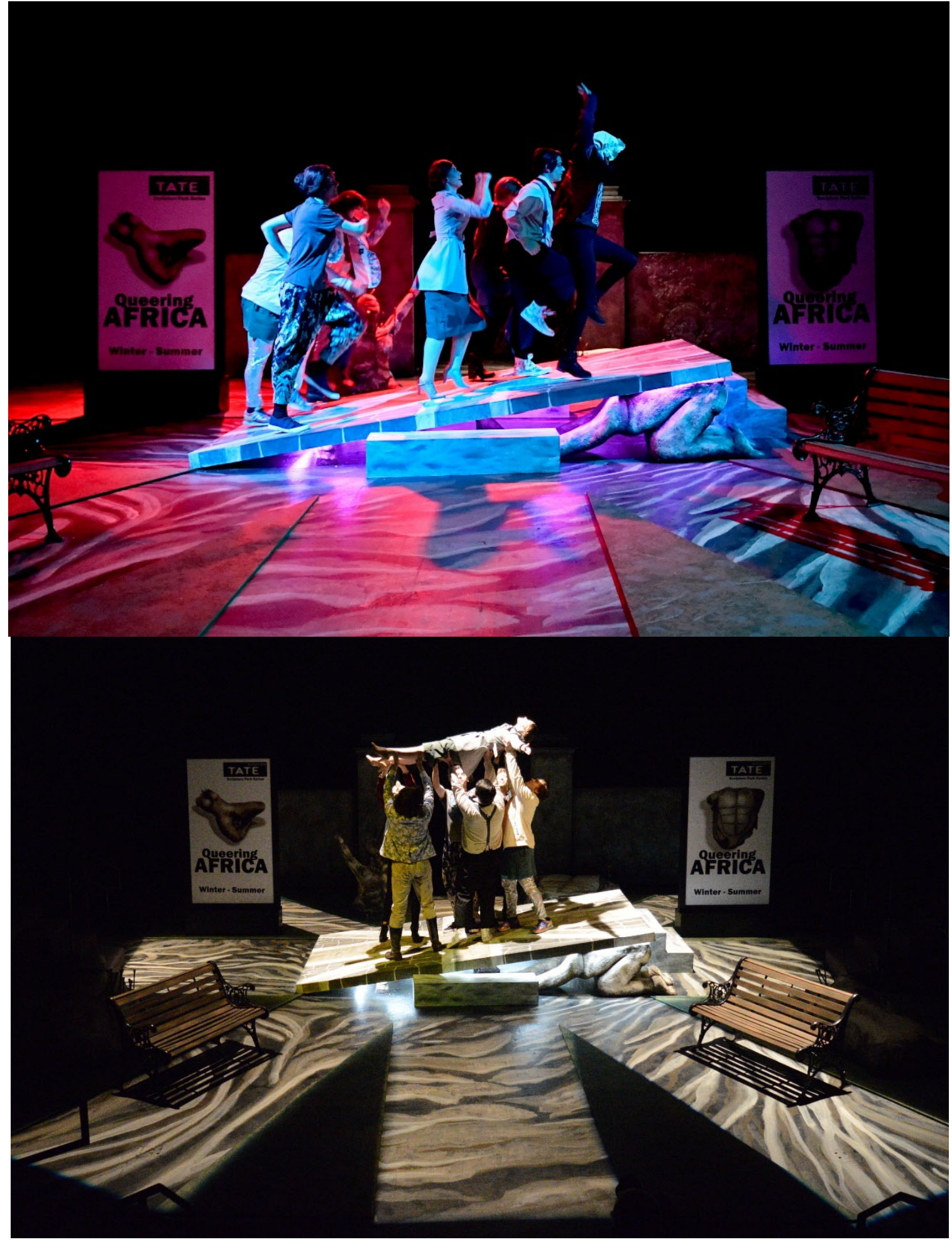




\section{Ace II Scene 2}

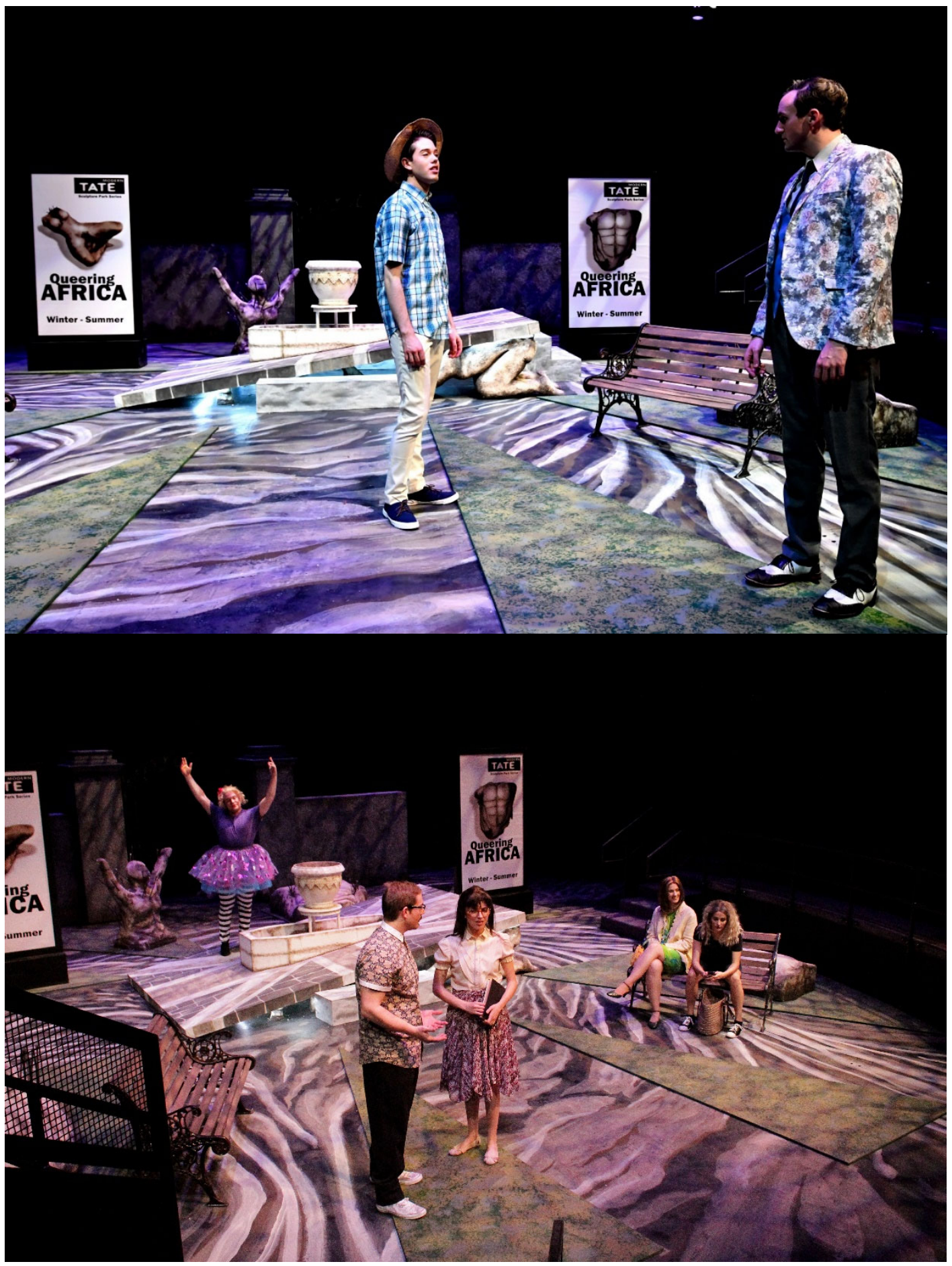




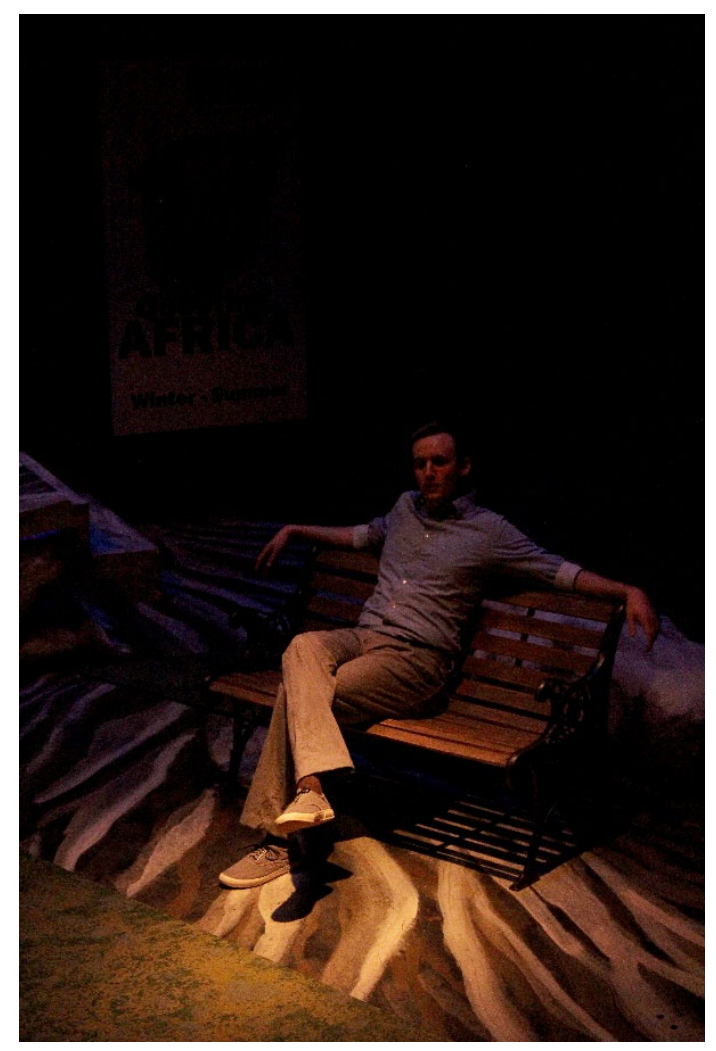

Act II Scene 3

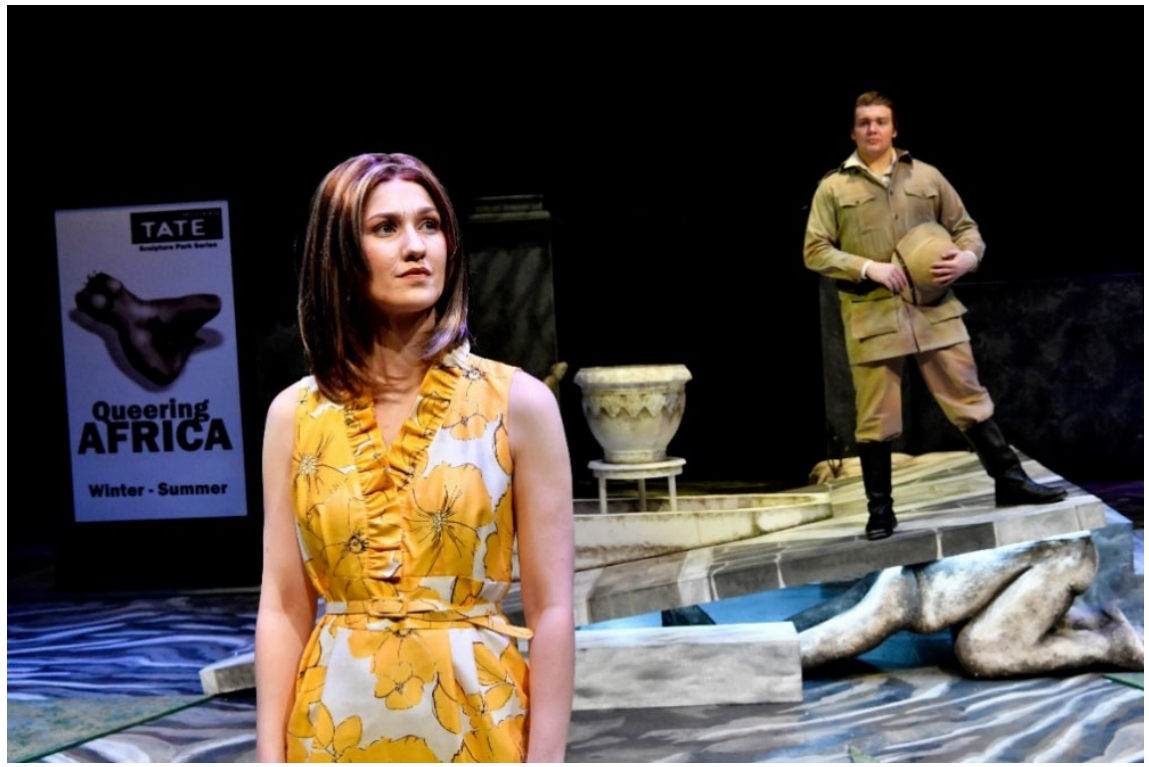

"You were not that sort of woman, Betty" 


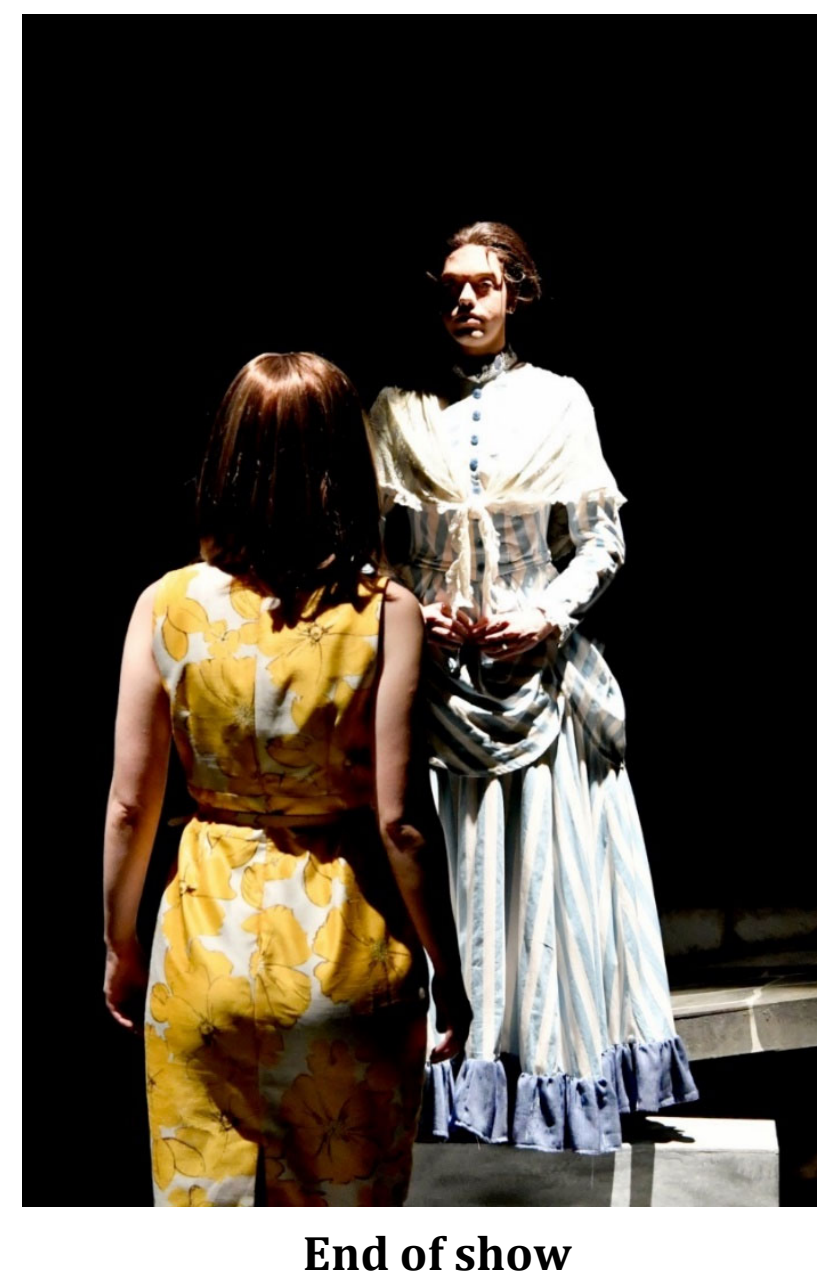

